\title{
Post-critical SsPmp and its Applications to Virtual Deep Seismic Sounding (VDSS)-3: Back-projection Imaging of the Crust-Mantle Boundary in a Heterogeneous Lithosphere, Theory and Application
}

\author{
Tianze Liu ${ }^{1,2}$ (tianze@stanford.edu), Simon L. Klemperer ${ }^{1}$, Chunquan Yu ${ }^{3}$, Jieyuan Ning ${ }^{4}$ \\ 1. Department of Geophysics, Stanford University \\ 2. Now at Institute of Geophysics and Planetary Physics, Scripps Institution of Oceanography, UC San Diego \\ 3. Department of Earth and Space Sciences, Southern University of Science and Technology \\ 4. Institute of Theoretical and Applied Geophysics, School of Earth and Space Science, Peking University
}

\section{SUMMARY}

Virtual Deep Seismic Sounding (VDSS) uses the arrival time of post-critical SsPmp relative to the direct $\mathrm{S}$ wave to infer Moho depth at the Pmp reflection point. Due to the large offset between the virtual source and the receiver, SsPmp is more sensitive to lateral variations of structures than near-vertical phases such as $P s$ that is used to construct conventional P receiver functions. However, the way post-critical $S s P m p$ is affected by lateral variations in lithospheric structures is not well understood, and previous studies largely assumed a 1D structure when analyzing SsPmp waveforms. Here we present synthetic tests with various 2D models to show that lateral variations in lithospheric structures, from the lithosphere-asthenosphere boundary to sedimentary basins, profoundly affect travel time, phase and amplitude of post-critical SsPmp, and that a 1D approximation is usually inappropriate when analyzing 2D data. Despite these strong effects we show, with synthetic examples and the ChinArray data from the Ordos Block in northern China, that a simple ray-theory-based back-projection method can retrieve the geometry of the crust-mantle boundary given array observations in cases with moderate lateral variations in the crust-mantle boundary and/or the lithosphere-asthenosphere boundary. The success of our back-projection method indicates that ray-theory approximations are sufficient in modeling SsPmp travel times in the presence of moderate lateral heterogeneity. In contrast, we show that the ray theory is generally insufficient in modeling SsPmp phase shifts in a strongly heterogeneous lithosphere due to non-planar down-going $\mathrm{P}$ waves incident at the crust-mantle boundary. Nonetheless, our results demonstrate the feasibility of direct imaging of the crustmantle boundary with post-critical SsPmp even in the presence of 2D variations of lithospheric structures.

KEYWORDS: Body waves, Crustal imaging, Crustal structure Composition and structure of the continental crust, Asia, Cratons 


\section{INTRODUCTION}

Virtual Deep Seismic Sounding (VDSS) has recently emerged as a novel method to image the crust-mantle boundary (CMB) and been successfully applied to multiple datasets from different areas (e.g. Kang et al., 2016; Luo et al., 2018; Parker et al., 2016; Thompson et al., 2019; Tian et al., 2015; Tseng et al., 2009; Yu et al., 2012, 2016). In keeping with the first two parts of our series paper (Liu et al., 2018, 2019, hereafter Part 1 and 2 respectively), here we use CMB (crust-mantle boundary) to denote the boundary or geological transition from crust to mantle, and Moho to denote a seismological inference about this transition, typically given as a single depth. SsPmp, the seismic phase used in VDSS, originates when upcoming teleseismic S waves convert to down-going $\mathrm{P}$ waves at the free surface (at the virtual source) and then undergo a post-critical reflection at or within the CMB before finally reaching the receiver (Fig. 1). In Part 1 and 2, we studied the sensitivity of SsPmp to lithospheric structures and developed methods to infer parameters of the crust and mantle from $S s P m p$ waveforms recorded at a single station, assuming a 1D Earth strucuture. Due to the large offset between the virtual source and the receiver (typically $>100 \mathrm{~km}$ for continental crust), post-critical $S s P m p$ is more sensitive to lateral variation along its ray path than near-vertical phases such as $P s$ (Fig. 1). However, previous studies largely assumed a 1D structure when analyzing $S s P m p$ waveforms (e.g. Yu et al., 2012; Tseng et al., 2009; Tian et al., 2015). Yu et al. (2016) noted that lateral (2D) variation in lithospheric $V_{s}$ causes travel-time differences between the up-coming $\mathrm{S}$ legs of SsPmp and Ss that are incorrectly included in estimated crustal thickness if a 1D approximation is used (see also Figure 11 in Part 1). Yu et al. (2016) proposed an array-based method to empirically correct for the effects of lateral $V_{s}$ variation. However, when $S s$ arrival time as a function of distance deviates from the 1D prediction, the ray parameters of $S s$ and of SsPmp differ due to lateral heterogeneity and vary with distance differently from the 1D case. How this variation affects $T_{V D S S}, \Phi_{V D S S}$, and $A_{V D S S}$ (respectively the relative arrival time, angular phase shift and amplitude of $S S P m p$ with respect to direct $S s$ ) is not immediately clear. 
In review with Geophysical Journal International

Here, we present 2D synthetic tests to demonstrate the effects of lateral heterogeneity on $T_{V D S S}, \Phi_{V D S S}$, and $A_{V D S S}$. In order to image the CMB with SsPmp in the presence of lateral variation in lithospheric structures, we present a simple ray-theory-based back-projection method that accounts for both lateral variation in $S s$ arrival times and ray parameters. We show that our method is capable of modeling $T_{V D S S}$ and retrieving the geometry of the CMB using observations along a linear array. On the other hand, we show that ray-theory approximations are insufficient to model $\Phi_{V D S S}$ because the plane-wave approximation fails in the presence of lateral heterogeneity. Finally, we demonstrate the success of our back-projection method in recovering an image of the dipping Moho beneath the Ordos Block in China, in a region with lateral variation in lithospheric thickness as well as crustal thickness.

\section{SYNTHETIC EXAMPLES}

To study the potential effects of lateral heterogeneity in the lithosphere on SsPmp waveforms, we use the SPECFEM2D software package to compute 2D synthetic waveforms (Komatitsch et al., 2001; Komatitsch and Vilotte, 1998; Tromp et al., 2008). Our models consist of three layers: crust, lithospheric mantle, and asthenosphere. Fig. 2a shows the material properties of each layer in the format $V_{p} / V_{s} /$ density, which are held constant across all models in this paper. The incident wave is set to be a planar $\mathrm{S}$ wave with an incident angle of $35^{\circ}$ in the asthenosphere $\left(p_{0}=0.1275 \mathrm{~s} / \mathrm{km}, 1 / p_{0}=7.84 \mathrm{~km} / \mathrm{s}\right)$ for all models (Fig. 2a). Our source time function is a first-order Hermitian wavelet (first derivative of Gaussian wavelet) with the dominant frequency $\sim 0.25 \mathrm{~Hz}$. This wavelet is similar in shape and frequency component to the source time functions of deep and intermediate-depth earthquakes that we use later (Section 3; Fig. 12). We compute velocity seismograms, although whether the seismograms are in velocity or displacement is unimportant to our analysis below. We place receivers at the free surface with $10 \mathrm{~km}$ spacing. We then vary the geometries of the CMB (here a sharp boundary) and lithosphere-asthenosphere boundary (LAB) to show their effects on SsPmp waveforms. Section 2.1 (Figs. 2-4, and S3-4) considers a sinusoidal LAB beneath a flat CMB. Section 2.2 (Figs. 5, 6, 8, and S5-6) models a sinusoidal CMB above a flat LAB. Section 2.3 (Figs. 9, and S7-9) studies a sinusoidal LAB beneath a sinusoidal CMB. Section 2.4 (Fig. 10) studies a sedimentary basin above flat CMB and LAB. We consider sinusoidal CMB varying between 30 and $50 \mathrm{~km}$ depth (amplitude $2 A=20 \mathrm{~km})$ and sinusoidal LAB varying between 80 and $200 \mathrm{~km}$ depth $(2 A=$ 
In review with Geophysical Journal International

$120 \mathrm{~km}$ ). We test topographic wavelengths $\lambda=1200 \mathrm{~km}, 600 \mathrm{~km}$ and $400 \mathrm{~km}$, so for the CMB $2 \mathrm{~A} / \lambda=0.0167,0.0333$ and 0.0500 , and for the $\mathrm{LAB} 2 \mathrm{~A} / \lambda=0.1,0.2,0.3$. The average boundary $\operatorname{dip} \theta_{a v}$ is a reasonable proxy for model complexity because steeper topography causes more raypath bending. Our models have $\theta_{a v}=2^{\circ}, 4^{\circ}$, and $6^{\circ}$ respectively for the CMB, and $\theta_{a v}=11^{\circ}, 22^{\circ}$, and $31^{\circ}$ for the LAB. For our models we choose the amplitude of the LAB topography to be six times the CMB topography in order to give similar variability in $S s$ travel time residuals $(\sim 1 \mathrm{~s})$ for the $\pm 60 \mathrm{~km} \mathrm{LAB}$ variation and for the $\pm 10 \mathrm{~km}$ CMB. This ratio of LAB-to-CMB topography sensibly approximates the real earth: in the northern Basin and Range Province of the western U.S.A., the CMB has $\lambda=\sim 400 \mathrm{~km}$ and $2 A=\sim 7 \mathrm{~km}$, with $\theta_{a v}=\sim 2^{\circ}$ (Klemperer et al., 1986), while the LAB in the region shows no significant variation (Hopper and Fischer, 2018) (cf. model in Fig. 5). At the boundary between the western and eastern North China Craton, the Moho deepens westward from $30-40 \mathrm{~km}$ across $\sim 200 \mathrm{~km}$ (Jia et al., 2014), with $\theta_{a v}=\sim 3^{\circ}$, while the LAB deepens westward from 80-200 km across $\sim 600 \mathrm{~km}$, with $\theta_{a v}=\sim 11^{\circ}$ (Chen et al., 2009) (cf. model in Fig. S7). At the boundary between the southern Sierra Nevada and the Basin and Range Province, the CMB has $\lambda=\sim 300 \mathrm{~km}$ and $2 A=\sim 10 \mathrm{~km}$, with $\theta_{a v}=\sim 4^{\circ}$, while the LAB varies approximately in phase with $\mathrm{CMB}$ and has $\lambda=\sim 300 \mathrm{~km}$ and $2 A=\sim 60 \mathrm{~km}$, with $\theta_{a v}=\sim 22^{\circ}$ (Fliedner et al., 1996) (cf. model in Fig. S9). The northern Basin and Range is representative of $\mathrm{CMB}$ and $\mathrm{LAB}$ variation within one geologic province, whereas the boundaries between southern Sierra Nevada and Basin and Range, and between the eastern and western North China Craton are representative of CMB and LAB variation between different geologic provinces that likely differs in lithosphere velocity structure not captured in our models. In our test models, the LAB is set as a sharp boundary for simplicity, whereas in reality the LAB may span tens of kilometers (Fischer et al., 2010). However, for the same total velocity change across the LAB, a sharp and a transitional LAB will have the same effect on SsPmp waveforms. We note that the average CMB and LAB dips chosen for our smoothest (Figs. 2a, 5a, S7) and intermediate (Figs. 3a, 6a, 9a) models are similar to the aforementioned examples, which makes them appropriate for studying the effects of lateral structural variation on real $S_{s} P m p$ waveforms. Our most extreme models (Figs. 4a, 8a, S9a) serve to demonstrate the very real limits of our methodology, albeit in circumstances not often encountered in reality.

\subsection{Effects of LAB Topography}


In review with Geophysical Journal International

We model a flat CMB at $40 \mathrm{~km}$ depth, and a sinusoidal LAB varying between 80 and 200 km-depth. We vary the wavelength of the LAB from $1200 \mathrm{~km}$ (Fig. 2a), through $600 \mathrm{~km}$ (Fig. 3a), to $400 \mathrm{~km}$ (Fig. 4a) to test its effect on SsPmp waveforms.

\subsubsection{Effects of gentle dips}

We start with the $1200 \mathrm{~km}$-wavelength case, in which the average dip of the LAB is $\sim 11^{\circ}$ (Fig. 2a). Fig. 2b shows vertical-component waveforms (containing both $\mathrm{P}$ and $\mathrm{S}$ energy) plotted against receiver locations and reduced travel times calculated with an apparent velocity of $V_{\text {app }}=$ $1 / p_{0}=7.84 \mathrm{~km} / \mathrm{s} ; S s, S s P m p$, and $S s P m p P m p$ are clear across the profile (Fig. 2b). Ss arrival times oscillate around zero time due to lateral velocity variations, indicating a non-planar wave is incident at the free surface. Because the source plane wave is incident from the lower left of the model, the early (late) arrivals of Ss are displaced to the right of the causative high (low) velocity variations. To further align the traces, we separate the waveforms into pseudo-P (motion associated with incoming $\mathrm{P}$ wave) and pseudo-S (motion associated with incoming $\mathrm{S}$ wave) components with a particle-motion-analysis algorithm (Yu et al., 2013) (Fig. S1) and apply a multi-channel cross-correlation (MCCC) on the pseudo-S-component waveforms, which are assumed to contain only Ss (See Supplementary Text 1). We use MCCC to align the seismograms to the peak of envelope functions of their $S s$ arrivals. The aligned vertical and pseudo-P components are shown in Fig. 2c and Fig. S1b respectively. After alignment we observe $\sim 1 \mathrm{~s}$ variation of $T_{V D S S}$ across the profile due to the $1200 \mathrm{~km}$-wavelength variation in LAB depth, which could be misinterpreted as Moho depth variation on the order of $5 \mathrm{~km}$ (Figs. $2 \mathrm{c}$ and $\mathrm{S} 1 \mathrm{~b})$. This potential pitfall highlights the importance of correcting for lateral heterogeneity effects when converting $T_{V D S S}$ to Moho depth (cf. Figure 11 in Part 1).

In order to better understand the behavior of the SPECFEM-modeled wavefield, we trace rays through our model and compare the ray-path distributions with the synthetic waveforms. For Ss, we shoot $\mathrm{S}$ rays with a constant take-off angle of $35^{\circ}$ from $10 \mathrm{~km}$-spacing starting points at the bottom of the model. The S rays undergo Snell's-Law refraction and reflection en route to the surface (Fig. 2h). We compute the "theoretical Ss ray parameter" of each ray from its incident angle at the free surface and plot it at its free-surface (i.e. virtual-source) location (gray curve in 
In review with Geophysical Journal International

Fig. 2d). As a result of the lateral variation in velocity structure, the $S s$ ray parameters vary between 0.1258 and $0.1301 \mathrm{~s} / \mathrm{km}$ (Fig. 2d). Alternatively, we can compute the "apparent $S s$ ray parameter" at the free surface by differentiating the $S s$ arrival time with respect to distance. Our apparent and theoretical Ss ray parameters agree well (Fig. 2d), which indicates that in this case apparent $S s$ ray parameters directly calculated from observed waveforms are equivalent to the theoretical $S s$ ray parameters that can only be derived if the velocity structure is known. After ray tracing for $S s$, we trace down-going P rays from the free-surface locations where each $S s$ ray terminates, assigning each $\mathrm{P}$ ray the same ray parameter as the corresponding $S s$ ray because our free surface is flat. The $\mathrm{P}$ rays then undergo reflection at the CMB and return to the surface (Fig. 2i). This procedure is equivalent to tracing P rays with the theoretical Ss ray parameters, the values of which are generally unevenly distributed at the surface due to the unevenly distributed $S s$ rays. An alternative way to compute $P m p$ ray paths is to trace the $\mathrm{P}$ rays with the apparent $S s$ ray parameters, which, in our case, are evenly distributed due to constant station spacing (Fig. 2j). The Pmp ray paths traced with the theoretical $S s$ ray parameters better account for $S s P m p$ amplitude variation because they incorporate the uneven distribution of Ss rays at the surface, which represents the distribution of Ss energy at the surface. However, we cannot derive the theoretical Ss ray parameters without knowing the true velocity model, so ray tracing for field data can only be conducted with apparent Ss ray parameters. Nonetheless, computeing ray paths with both methods throughout this paper is instructive. For our $1200 \mathrm{~km}$-wavelength LAB, the Pmp rays traced with the two methods are nearly both identical and uniformly spaced (Figs. 2i, j) because the distribution of Ss rays is nearly uniform at the surface (Fig. 2h).

In this model with a flat $\mathrm{CMB}, p_{V D S S}$, the apparent ray parameter of the incident $\mathrm{P}$ ray at the $\mathrm{CMB}$ is equal to the $S s$ ray parameter $p_{S s}$ at its virtual source, so of course it varies along the profile. We might expect that $\Phi_{V D S S}$ also changes along the profile due to its sensitivity to ray parameters in 1D structure (Part 1). To test whether our relation between $p_{V D S S}$ and $\Phi_{V D S S}$ in 1D still holds in the presence of $2 \mathrm{D}$ variation, we measure $\Phi_{V D S S}$ from our synthetic waveforms (apparent $\Phi_{V D S S}$; thin black curve in Fig. 2e) and compare with $\Phi_{V D S S}$ predicted with ray theory (theoretical $\Phi_{V D S S}$; thick grey curve in Fig. 2e). We measure apparent $\Phi_{V D S S}$ by minimizing the root-mean-square misfit between the observed $S s P m p$ and a synthetic $S s P m p$ computed by applying different phase-shifts to the source wavelet (Part 2). We align the synthetic and the observed SsPmp with cross-correlations before calculating the misfit. In contrast, we calculate 
In review with Geophysical Journal International

the theoretical $\Phi_{V D S S}$ from the complex reflection coefficient at the CMB, which is determined by $p_{V D S S}$ and the velocity change across the CMB under the assumption of a planar incident wave (Aki and Richards, 2002). We plot the apparent $\Phi_{V D S S}$ at the receiver locations where they were measured, and the theoretical $\Phi_{V D S S}$ values at the locations where the reflected $\mathrm{P}$ rays reach the free surface as predicted by the ray tracing (the VDSS surfacing points) (Fig. 2e). Minor discrepancies up to $15^{\circ}$ between the apparent and theoretical $\Phi_{V D S S}$ (Fig. 2e) are primarily caused by the curved (non-planar) incident wave front at the CMB. Our plane-wave approximation (theoretical $\left.\Phi_{V D S S}\right)$ under-predicts apparent $\Phi_{V D S S}$ where $p_{V D S S}$ increases with distance (retrograde; virtual sources west of $800 \mathrm{~km}$ in Fig. $2 \mathrm{~d}$ corresponding to surfacing points west of $920 \mathrm{~km}$ in Fig. 2e), but over-predicts apparent $\Phi_{V D S S}$ where $p_{V D S S}$ decreases with distance (prograde; virtual sources at 800-1400 km, Fig. 2d, and surfacing points from 920-1520 km,

Fig. 2e). Teleseismic $\mathrm{S}$ waves are prograde (ray parameter $p_{S s}$ decreases with increasing epicentral distance). Because the slope of $p_{S s}$ as a function of distance $\left(\sim 1.6 \times 10^{-5} \mathrm{~s} / \mathrm{km} / \mathrm{km}\right)$ is similar to the slope of ray parameter due to LAB undulation in this example $\left(\sim 1.4 \times 10^{-5}\right.$ $\mathrm{s} / \mathrm{km} / \mathrm{km})$, theoretical $\Phi_{V D S S}$ computed with a planar incident P wave at the CMB likely overpredicts the $\Phi_{V D S S}$ of real $S \mathrm{~s} P m p$, even if the planar P wave and the real $S s P m p$ have the same $p_{\text {VDSS }}$ (Supplementary Text 2). To further study the effects of a curved $\mathrm{P}$ wave front, we calculate the upper-mantle $V_{p}$ (hereafter $V_{p}^{u m}$ ) from the apparent $\Phi_{V D S S}$ under the plane-wave assumption and plot $V_{p}^{u m}$ at the corresponding Pmp reflection points (Fig. 2f). Our inferred $V_{p}^{u m}$ shows up to $\pm 1.5 \%$ deviation from the true value $(8.30 \mathrm{~km} / \mathrm{s}$; Fig. $2 \mathrm{f})$, which is modest compared to the range of $P n$ velocity variation ( $4.5 \%)$ in the contiguous U.S.A. (Buehler and Shearer, 2017). If we use more distant teleseismic events with larger $1 / p_{V D S S}$ closer to the true $V_{p}^{u m}$, the error in estimated $V_{p}^{u m}$ will likely decrease because $\Phi_{V D S S}$ becomes increasingly sensitive to $V_{p}^{u m}$ as $1 / p$ approaches $V_{p}^{u m}$ (Figure 7 in Part 1), thus a fixed error in $\Phi_{V D S S}$ causes a smaller error in $V_{p}^{u m}$.

\subsubsection{Moho imaging by $S s P m p$ back-projection}

Above, we began to explore how 2D lithospheric variations affect $T_{V D S S}, \Phi_{V D S S}$, and $A_{V D S S}$ We next develop a simple ray-tracing-based back-projection method to image CMB geometry from observed SsPmp waveforms in a laterally heterogeneous Earth, utilizing a linear recording array. To address $\Phi_{V D S S}$ variation across the array, we correct all pseudo-P-component 
In review with Geophysical Journal International

traces to $90^{\circ}$ phase shift using the apparent $\Phi_{V D S S}$ (e.g. thin black curve in Fig. 2e) before applying back projection. Because the source wavelet used for our synthetic examples is antisymmetric the wavelet becomes symmetric after a $90^{\circ}$-phase-shift, with the arrival time at its maximum (Figs. S1b, c). To back-project the data, we shoot $\mathrm{P}$ rays downward from each virtual source location $x_{s r c}$ using apparent $S s$ ray parameters derived by differentiating the $S s$ arrival times that are sampled at our regular $10 \mathrm{~km}$-receiver spacing. For each sequential possible Moho depth $H$ sampled at $1 \mathrm{~km}$ interval, we compute the two-way $\mathrm{P}$ travel-time $T_{\text {ref }}$ of a hypothetical horizontal reflector at that depth by:

$$
T_{\text {ref }}=\frac{2 H}{V_{p}^{a v} \sqrt{1-V_{p}^{a v 2} p_{S S}^{2}}}
$$

where $V_{p}{ }^{a v}$ is the average crustal $V_{p}$, and $p_{S s}$ is the $S s$ ray parameter (as used for the down-going $\mathrm{P}$ ray). For a flat Moho, the location where the reflected Pmp ray reaches the surface (hereafter surfacing point) is:

$$
x_{s r f}=x_{s r c}+\frac{2 H V_{p}^{a v} p_{S s}}{\sqrt{1-V_{p}^{a v 2} p_{S s}^{2}}}
$$

where $x_{s r c}$ is the spatial coordinate of the virtual source. The differential travel time between $S s$ at the virtual source and $S s$ at the surfacing point is:

$$
\Delta T_{S s}=T_{S s}\left(x_{s r c}\right)-T_{S S}\left(x_{s r f}\right)
$$

which is measured with MCCC. Therefore, the travel time of $S s P m p$ relative to $S s$ (i.e. $T_{V D S S}$ ) for this particular ray is:

$$
T_{V D S S}=T_{\text {ref }}+\Delta T_{S S}
$$

We apply linear interpolation to the phase-shift-corrected pseudo-P-component traces (recorded at uniformly-spaced receivers; Fig. S1c) to find the energy at $\left(x_{s r f}, T_{V D S S}\right)$ for each calculated $x_{s r f}$ (Eqn. 2) and place it at depth $H$ vertically below the midpoint between the virtual-source location and the surfacing point. To account for finite-frequency effects, we laterally smear the energy of each ray with a Gaussian function with standard deviation $\sigma$ equal to the Fresnel zone radius at the corresponding depth (for our $4 \mathrm{~s}$-period source wavelet, $\sigma=\sim 30 \mathrm{~km}$ for $H=40 \mathrm{~km}$ ). We repeat this procedure for the $\mathrm{P}$ ray from every virtual-source location to form the final image (Figs. 2g, k). Because the maximum amplitude on each phase-shift-corrected trace is at $T_{V D S S}$ we pick the maximum amplitude on each column of the image as the estimated Moho depth at that 
location (solid black curve in Fig. 2k). The resulting back-projection image shows the Moho image at the correct CMB depth along the profile (Figs. $2 \mathrm{~g}, \mathrm{k}$ ). We also compute the backprojection image with a constant $S s$ ray parameter $p=p_{0}=0.1275 \mathrm{~s} / \mathrm{km}$, which is equivalent to back projection with the 1D travel-time equation for SsPmp:

$$
T_{V D S S}=2 H \sqrt{\frac{1}{V_{p}^{a v 2}}-p_{0}^{2}}
$$

This procedure gives the "uncorrected" Moho depth estimates (black dashed curve in Fig. 2k) that show an apparent variation of Moho depth across the profile, which is an artifact caused by lateral variation in the mantle. Thus, the black dashed curve represents the Moho depth that has been interpreted using existing methods and is likely to include significant errors in areas where LAB and CMB topography are inferred (e.g. Yu et al., 2012; Tian et al., 2015). This phenomenon emphasizes the importance of incorporating Ss ray parameter (thus travel-time) variation in $S s P m p$-waveform analysis.

\subsubsection{Additional effects of steeper dips}

We next reduce the $\mathrm{LAB}$ wavelength to $600 \mathrm{~km}$ and repeat the process (Fig. 3). The average dip of the LAB is now $\sim 22^{\circ}$ (Fig. 3a). The resulting $S s$ and $S s P m p$ arrival times show stronger variations compared with the $1200 \mathrm{~km}$-wavelength case (Figs. 3b, c). As a result of the stronger $S s$ arrival-time variation, the apparent ray parameter also varies more strongly than the $1200 \mathrm{~km}$-wavelength case (thin black curve in Fig. 3d). The $S s$ rays are slightly denser at $\sim 980$ and $\sim 1580 \mathrm{~km}$ than elsewhere due to the focusing effects of a shallow LAB (Fig. 3i). The theoretical Ss ray parameters computed with ray tracing (thick gray curve in Fig. 3d) agree well with the apparent $S s$ ray parameters (thin black curve in Fig. 3d). We then trace Pmp rays with the apparent and theoretical Ss ray parameters, finding increased Pmp ray density at $\sim 1100$ and $\sim 1700 \mathrm{~km}$ for both the rays traced with the theoretical and apparent ray parameters, with the former having stronger ray density variation than the latter (Figs. 3j, k). For the Pmp rays traced with the theoretical ray parameters, the reason for high ray density is twofold. First, the Ss ray density is higher at the corresponding virtual source locations ( 980 and $\sim 1580 \mathrm{~km}$; Fig. 3i). Second, the $S s$ ray parameter changes from retrograde to prograde at these virtual source locations ( $\sim 980$ and $\sim 2180 \mathrm{~km}$; Fig. 3d), causing the ray parameters, thus the incident angles at the CMB, of the Pmp rays to first increase than decrease, which produces additional focusing 
effects for the Pmp rays. For the Pmp rays traced with the apparent ray parameters (Fig. 3k), only the second effect exists as the virtual sources are equally spaced in this case, which explains the weaker focusing effect. Due to the increased irregularity of the incident $S s$ wave front compared with the $1200 \mathrm{~km}$-wavelength model in Fig. 2, the discrepancy between the theoretical and apparent $\Phi_{V D S S}$ increases significantly (Fig. 3e). As a result, the discrepancy between the inferred and true $V_{p}^{u m}$ grows to $\sim 4.5 \%$. However, although a significant lateral variation of lithospheric structure means that ray-theory approximations are insufficient to model $\Phi_{V D S S}$, our backprojection method still recovers the CMB depths reasonably well. Our back-projection image shows the Moho depth at $40 \pm 2 \mathrm{~km}$ along the profile, close to the $40-\mathrm{km} \mathrm{CMB}$ depth in the original model (Figs. 3g, 1). The Moho amplitude variation in our back-projection image (Figs. $3 g, 1)$ results from the uneven Pmp ray distribution. The amplitude is highest at $\sim 1100 \mathrm{~km}$ where the CMB has the highest density of Pmp reflections points (Figs. 3j, k). As expected, the difference between the corrected and uncorrected Moho depth estimates grows due to the stronger lateral heterogeneity (Fig. 31). We also tested stacking the back-projection images of two earthquakes, one from the west and one from the east, both with the same incident angle (35 ; Figs. 3h, m). The resulting image gives an improved Moho depth estimation and smoother amplitude than given by a single earthquake (Figs. $3 \mathrm{~h}, \mathrm{~m}$ ).

Finally, we reduce the LAB wavelength to $400 \mathrm{~km}$, and the average dip of the LAB becomes $\sim 31^{\circ}$ (Fig. 4a). The waveforms now show strong variation in the arrival times and the amplitude of $S s$ and $S s P m p$ (Figs. 4b, c). Besides $S s$ and $S s P m p$, we observed additional seismic phases that can be fitted by a hyperbola with a source depth of $200 \mathrm{~km}$ (largest LAB depth) and a characteristic velocity of $4.61 \mathrm{~km} / \mathrm{s}$ (lithospheric-mantle $V_{s}$ ) (H1 in Fig. 4b), and a hyperbola with a source depth of $40 \mathrm{~km}$ (CMB depth) and a characteristic velocity of $6.5 \mathrm{~km} / \mathrm{s}$ (crustal $V_{p}$ ) (H2 in Fig. 4b). H1 shows opposite polarity on vertical and radial components, a polarization consistent with $\mathrm{S}$ wave, whereas $\mathrm{H} 2$ shows the same polarity on vertical and radial components, consistent with P wave (Figs. S3b, c). Combining the moveouts and polarizations of the two phases, we interpret $\mathrm{H} 1$ as a diffracted $\mathrm{S}$ wave generated by the incident $\mathrm{S}$ wave at the deepest points of the LAB, and $\mathrm{H} 2$ as a diffracted $\mathrm{P}$ wave generated by $S s P m p$ at the CMB where $S s P m p$ rays undergo multipathing (e.g. $\sim 1100 \mathrm{~km}$; Figs. 4i, j and Fig. S3a). The ray tracing for Ss shows strong focusing atop the shallowest LAB from S rays traveling sub-parallel to the LAB (Fig. 4h). The strong $\mathrm{LAB}$ undulation also causes post-critical reflection at the LAB for a few $\mathrm{S}$ rays that 
In review with Geophysical Journal International

meet the LAB with very high incident angles (Fig. 4h). These post-critically reflected $\mathrm{S}$ rays are widely dispersed at the surface (Fig. 4h) and have ray parameters higher than the reciprocal of crustal $V_{p}(0.1538 \mathrm{~s} / \mathrm{km}$; Fig. $4 \mathrm{~d})$. This triplication behavior causes the $S s$ theoretical ray parameter to be multi-valued in the ranges $600-700 \mathrm{~km}, 1000-1100 \mathrm{~km}$ and 1400-1500 km (Fig. 4d) (Theoretical $p_{S s}$ at $\sim 1500 \mathrm{~km}$ and $\sim 1900 \mathrm{~km}$ is missing the high values seen at $\sim 700 \mathrm{~km}$ and $\sim 1100 \mathrm{~km}$ in Fig. 4d because the spacing of our initial Ss rays is not dense enough to capture the rapid variation of ray parameter at those two locations.) The apparent $p_{S s}$ generally agrees with the theoretical $p_{S s}$, except that the apparent $p_{S s}$ lacks any abnormally high values. This is because the apparent $p_{S s}$ derived from our synthetic waveforms only includes the first-arrival branch of the phase. Only very few of the rays with high $p_{S s}$ exist (Fig. $4 \mathrm{~h}$ ), limiting their contribution to the $S s$ waveforms. The results of P-ray tracing show a complicated pattern to the right of the shallowest parts of the LAB (Figs. 4i, j). In accord with the sharp peak of both apparent and theoretical Ss ray parameter vertically above the shallowest LAB (Fig. 4d), the take-off angles of down-going P rays first increase (retrograde branch) and then decrease with distance (prograde branch). The P rays of the two branches cross and cause focusing of SsPmp to the east (right) of the shallowest LAB (e.g. 1100 km; Figs. 4b, c, i, j), which generates H2 (Fig. S3a). For cases with CMB topography discussed below, the apparent ray parameters of incident P rays at the $\mathrm{CMB} p_{V D S S}$ will be different from and have more complex lateral variation than the $S s$ ray parameters. Due to the strongly non-planar $S s$ incident at the free surface the theoretical $\Phi_{V D S S}$ is significantly different from apparent $\Phi_{V D S S}$ (Fig. 4e). Despite the complicated $S s$ and $S s P m p$ waveforms, our back-projection method is still capable of imaging the CMB reasonably well, although the amplitude clearly varies along the Moho image (Figs. 4f, $\mathrm{k}$ ). The only places where the discrepancy between the imaged Moho and the CMB exceeds $3 \mathrm{~km}$ are $\sim 700-800 \mathrm{~km}$, $\sim 1100-1200 \mathrm{~km}$, and $\sim 1500-1600 \mathrm{~km}$, where the Moho depth estimates are deeper than the CMB (Figs. 4f, k). When comparing the corrected and uncorrected back-projection images in these ranges, we find that both images overestimate the Moho depth, though the discrepancy in the corrected image is significantly smaller than the uncorrected one (Fig. 4k). Therefore, the error in our corrected back-projection image can be understood as insufficient correction for the Ss travel-time variation. Including an earthquake from the opposite direction gives a smoother amplitude variation along the Moho image but yields little improvement in Moho depth estimate (Fig. 41). 
In review with Geophysical Journal International

To test the effects of different initial S-wave incident angles, we also compute waveforms with incident angle of $33^{\circ}$ and conducted back projection with the synthetic data (Fig. S4). The image of the $33^{\circ}$ earthquake (Figs. S4a, f) gives similar Moho depth estimations and shows similar amplitude variation as the $35^{\circ}$ one (Figs. $4 \mathrm{~b}, \mathrm{~g}$ ) because the focusing and defocusing of Pmp rays happen at similar locations for both events. Due to the similarity between the $33^{\circ}$ and $35^{\circ}$ images, stacking them only yields limited improvement for the Moho depth estimations (Figs. S4c, h). Even including four earthquakes with both incident angles from both west and east only slightly improves the Moho depth estimations (Figs. S4e, j).

\subsection{Effects of CMB Topography}

In this section, we fix the LAB at $200 \mathrm{~km}$ depth and model a sinusoidal CMB (Figs. 5, 6, 8). We fix the peaks and troughs of the $\mathrm{CMB}$ at 30 and $50 \mathrm{~km}$ depth and test $\mathrm{CMB}$ wavelengths of 1200,600 , and $400 \mathrm{~km}$. The incident angle of the initial planar S wave in the asthenosphere is fixed at $p_{0}=35^{\circ}$, as in our previous models.

We first set the CMB wavelength as $1200 \mathrm{~km}$, so the average dip of the CMB is $\sim 2^{\circ}$ (Fig. 5a). The synthetic waveforms aligned with an apparent velocity $V_{a p p}=1 / p_{0}=7.84 \mathrm{~km} / \mathrm{s}$ show a smooth sinusoidal change of $S s$ arrival time caused by the sinusoidal variation of CMB depth (Fig. 5b). we observe clear SsPmp after Ss 1 showing similar sinusoidal variation pattern but with a much larger range (Fig. 5b), that is, $S s P m p$ arrival times are more sensitive to CMB variation than $S s$ arrival times (cf. Fig. 2). In addition to $S s$ and $S s P m p$, we observe another significant phase after $S_{S} P m p$ with similar travel-time variation but lower amplitude, likely SsPmpPmp (Fig. 5b). The down-dip branch of SsPmpPmp is significantly amplified compared to the up-dip branch due to the lateral variation of CMB depth, (Fig. 5b; up-dip and down-dip refer to interfaces slopes with dip directions towards or away from the incoming direction of the source). SsPmpPmp and other multiple P phases (e.g. SsPmsPmp; Thompson et al., 2019; Yu et al., 2013) are not further discussed in this paper but could in future be incorporated into back projection or other imaging schemes. We apply the aforementioned ray-tracing scheme for $S s$ and observe negligible focusing effects, corresponding to minor change of $S s$ amplitude across the profile (Fig. $5 \mathrm{~g}$ ). As a result of the smooth variation of the $S s$ arrival times, the theoretical and apparent Ss ray parameters are also quite close to $p_{0}=0.1275 \mathrm{~s} / \mathrm{km}$ (Fig. $5 \mathrm{~d}$ ), indicating relatively small deviation from a planar incident $S s$. The Pmp rays traced with theoretical and apparent $S s$ ray 
In review with Geophysical Journal International

parameters are almost identical, showing a near-uniform distribution of Pmp rays (Figs. $5 \mathrm{~h}, \mathrm{i}$ ). However, despite the minor variation of $S s$ ray parameter, the theoretical and apparent $\Phi_{V D S S}$ differ by up to $60^{\circ}$ (Fig. 5e). This discrepancy is likely caused by the non-planar CMB that makes Pmp deviate further from being planar. Specifically, the traced Pmp rays show pre-critical reflections (yellow rays in Figs. 5h, i) on the up-dip segment of the CMB and predict $\Phi_{V D S S}=$ $180^{\circ}$ there, which is not observed in the apparent $\Phi_{V D S S}($ Fig. 5e). We apply our back-projection method and observe that the imaged Moho agrees well with the CMB ( $\pm 2 \mathrm{~km}$; Figs. 5f, j), even though our back-projection scheme assumes horizontal reflectors, whereas the rays shown in Figs. 5h and i (also Figs. 6h, i, Figs. 8h, i, Figs. S7g, h, Figs. 9g, h, and Figs. S9g, h, and) are traced with the actual sinusoidal CMB geometry. Our corrected Moho depths are more consistent with the true CMB compared with the uncorrected estimates because our correction accounts for the lateral variation of $S s$ ray parameter (hence ray parameter; Fig. $5 \mathrm{j}$ ). The amplitude variation along the Moho is minor (Fig. 5f) due to the near-uniform distribution of the Pmp rays (Figs. 5h, i), even though $S s P m p$ varies from pre-critical to post-critical.

We next reduce the CMB wavelength to $600 \mathrm{~km}$ (average dip $\sim 4^{\circ}$ ) and compute synthetic waveforms (Fig. 6a). The resulting $S s$ and $S s P m p$ arrival times show sinusoidal variations with shorter wavelengths (Figs. 6b, c), and the up-dip and down-dip branches of SsPmpPmp become more asymmetric (Fig. 6b) due to the increased dip on the CMB. The traced Ss rays are still relatively uniform (Fig. 6g), but the $S s$ ray parameter shows a stronger sinusoidal variation than the $1200 \mathrm{~km}$-wavelength case (Fig. 6d). The traced Pmp rays shows significantly more uneven ray density and pre-critical reflections on the up-dip segments of the CMB (Figs. 6e, h, i). Although the presence of pre-critical reflections is again not shown by apparent $\Phi_{V D S S}$ measurements (apparent $\Phi_{V D S S}$ is always $<180^{\circ}$; Fig. 6e), it has an effect on $A_{V D S S}$ : The cyan trace has approximately the same amplitude as the blue one (Fig. 6k) despite having a higher incoming Pmp ray density (Figs. 6h, i) because the rays arriving at the cyan station are precritical, thus carrying lower amplitude than the post-critical rays (Figs. 6h, i). This inconsistent manifestation of pre-critical reflections on $\Phi_{V D S S}$ and $A_{V D S S}$ highlights the non-ray-theory behavior of the wavefield in this $\lambda=600 \mathrm{~km}$ case. Applying our back-projection scheme to the synthetic data yields a Moho image with higher amplitude at the CMB valleys and lower amplitude at the CMB ridges (Figs. 6f, j); the down-dip (up-dip) segments of the CMB are imaged at shallower (greater) depth (Figs. 6f, j). Two main factors contribute to the higher Moho 
In review with Geophysical Journal International

amplitude at the $\mathrm{CMB}$ valleys than the $\mathrm{CMB}$ ridges. First, the traces back projected to the $\mathrm{CMB}$ troughs have higher SsPmp amplitude (e.g. the green trace in Fig. 6k). Second, the CMB troughs have denser SsPmp reflection points (Figs. 6h, i). The same argument can explain the lower Moho amplitude at CMB peaks, where the SsPmp amplitude is low (e.g. the cyan trace in Fig. $6 \mathrm{k}$ ), and the $S s P m p$ reflection points are sparse (Figs. 6h, i). The discrepancies between the imaged Moho depth and the true CMB depth for a dipping CMB raise the question whether the horizontal-reflector assumption in our back-projection scheme makes the method unable to recover CMB dips precisely. The comparison of the corrected and uncorrected Moho depths shows that the uncorrected Moho depths show greater deviation from the CMB depth, but with the same polarity (Fig. 6j). As before (Fig. 4k), this comparison implies that the discrepancy between the corrected Moho depths and the true CMB is likely due to insufficiently corrected $S s$ travel time variations. By including another earthquake with the same incident angle from the opposite direction, the CMB slopes are significantly better imaged (Figs. S5c, d) because the depth biases for the two events are opposite, thus offsetting each other in the stacked image.

To further investigate the ability of our back-projection method to recover CMB dips, we compute synthetic SsPmp waveforms using models with planar CMB ramps and apply our backprojection scheme to them (Fig. 7). To test the effects of CMB dip directions and dip angles, we generate models with $\sim \pm 3^{\circ}$ (CMB depth changing from 30 to $50 \mathrm{~km}$ across $400 \mathrm{~km}$; positive indicates rays travelling in the down-dip direction; Figs. 7a, d) and $\sim \pm 6^{\circ}$ dip (CMB depth changing from 30 to $70 \mathrm{~km}$ across $400 \mathrm{~km}$; Figs. $7 \mathrm{~g}$, j). The initial ray parameter and the material properties are kept the same as previous examples. The vertical-component synthetic waveforms for the four earth models aligned to the $S s$ arrivals are shown in Figs. 7b, e, h, and k. We find that our back-projection method recovers the dipping angles of the CMB ramps well in all cases (Figs. 7c, f, i, 1), except for local discrepancies with ramp dip of $-6^{\circ}$ (Fig. 71). This discrepancy is likely due to strong multiples that locally interfere with SsPmp (Fig. 7k). These examples demonstrate that the horizontal-reflector assumption in our back-projection scheme is sufficient to image the $\mathrm{CMB}$ with dip $\leq \pm 6^{\circ}$. Since the CMB dip in the case with a $600 \mathrm{~km}$-wavelength $\mathrm{CMB}$ is $<6^{\circ}$ (Fig. 6), the discrepancies between our Moho image and the true CMB (Fig. 6j) are unlikely due to the horizontal-reflector assumption. Rather, we note that the peak-to-trough distance in Fig. 6 is less than in Fig. 7, and this rapid spatial variation is accentuated by the nonlinear, sinusoidal depth variation in Fig. 6. 
In review with Geophysical Journal International

We finally decrease the CMB wavelength to $400 \mathrm{~km}$ (average dip $\sim 6^{\circ}$; Fig. 8a) and compute synthetic waveforms. In addition to strong sinusoidal variation in $S s$ and $S s P m p$ arrival times (Figs. 8b, c), the SsPmp amplitude also varies dramatically, low on the up-dip branches and high on the down-dip branches (Figs. 8b, c, k). The distribution of the $S s$ rays remains relatively uniform (Fig. 8g), consistent with the small variation in $S s$ amplitude (Figs. 8b, c, k) and in contrast to $S s P m p$. As in the $600 \mathrm{~km}-\mathrm{CMB}$ case, the $S s P m p$ amplitude is controlled by the Pmp ray density and the energy carried by individual rays, as evidenced by the similar amplitude of the cyan and blue traces(Figs. 8k). The sharp changes in the theoretical $\Phi_{V D S S}$ at $\sim 900, \sim 1300$ and $\sim 1700 \mathrm{~km}$ (thick gray curve, Fig. 8e) are due to Pmp rays with a wide range of incident angles at the CMB arriving over a very narrow distance range (Figs. 8h, i). Our back-projection Moho image shows strong amplitude variation (Figs. 8f, j) due to the uneven distribution of the Pmp rays (Figs. 8h, i) and the strong variation of the $S s P m p$ amplitude (Figs. 8b, c, k). Although the corrected Moho depths (solid black curve in Fig. 8j) match the true CMB depths poorly in segments distant from the CMB valleys, they are still significantly better than the uncorrected Moho depths (dashed black curve in Fig. 8j). After including another earthquake from the opposite back azimuth, the CMB slopes are better resolved, and the amplitude distribution becomes more even (Figs. S6b, d, g, i), as in the $600 \mathrm{~km}-\mathrm{CMB}$ case. We again test the effects of including earthquakes with different incident angles. Surprisingly, the $33^{\circ}$ event gives a poorer Moho image than the $35^{\circ}$ event with artifacts near the CMB ridges (Figs. S6a, f) likely caused by locally weak SsPmp and strong SsPmpPmp (Figs. 8b, c). In this synthetic case, because the $33^{\circ}$ event yields a poorer Moho image than the $35^{\circ}$ event (Figs. S6a, b, f, g) including the $33^{\circ}$ event in the stack actually decreases the image quality (Figs. S6a, c, f, h). With real data, the improvement in signal-to-noise ratio from stacking additional waveforms might outweigh the loss of image quality from including events with different incident angles.

\subsection{Joint Effects of CMB and LAB Topography}

Finally, we study earth models in which both the CMB and the LAB show sinusoidal depth variation in order to test the ability of our back-projection method to image variations in CMB depth in the presence of LAB depth variation. We assign identical structural wavelengths and in-phase variations to the CMB and the LAB in our models, e.g. the CMB and LAB are both deep beneath collisional orogens and both shallow beneath rifts. We set depth ranges of the CMB 
In review with Geophysical Journal International

and the LAB as 30-50 km and 80-200 km, use the same material properties and initial S-wave incident angle as in the previous examples, and test structural wavelengths of 1200, 600, and 400 $\mathrm{km}$.

We first test our back-projection method on the model with a structure wavelength of $1200 \mathrm{~km}$ (Fig. S7a). The synthetic waveforms show very smooth variation of $T_{V D S S}$, and the SsPmp amplitude is almost constant across the profile (Figs. S7b, c, j). The multiple arrival is also visible following $S_{s} P m p$ (Fig. S7b and blue trace in Fig. S7j). The Ss ray parameter is very close to the initial ray parameter $p_{0}=0.1275 \mathrm{~s} / \mathrm{km}$ across the profile (Fig. S7d) because the inphase variation of the crustal thickness (low velocity) and the lithospheric-mantle thickness (high velocity) counteracts each layer's individual effects on $S s$ arrival time, making $S s$ at the free surface closer to a plane wave. As expected, our back-projection procedure recovers the CMB geometry almost perfectly ( $\pm 1 \mathrm{~km}$; Figs. S7e, i).

As we reduce the structure wavelength to $600 \mathrm{~km}$ (Fig. 9a), the $S s$ and $S s P m p$ arrival times show sinusoidal patterns with shorter wavelength (Figs. 9b, c). The variation of the Ss ray parameter (Fig. 9d) is less strong than for the case with a flat LAB and a $600 \mathrm{~km}$-wavelength CMB (Fig. 6d) due to the in-phase variation of crustal and lithospheric thickness. Similarly, the back-projection image resolves the CMB well with slightly improved images of the CMB slopes (Figs. 9e, i) compared to the case with a flat LAB and a $600 \mathrm{~km}$-wavelength CMB (Figs. 6f, j). As expected, the stack of earthquakes from both back azimuths further improves the Moho image (Figs. S8c, d). These results are encouraging because in-phase variations of CMB and LAB depth (Fig. 9a) may be more prevalent than a flat LAB beneath a variable CMB (Fig. 6a).

When the structure wavelength is reduced to $400 \mathrm{~km}$ (Fig. S9a), we observe absurdly complex waveforms resulting from both the lateral variation in CMB and LAB depths that would likely defy confident interpretations on real data (Figs. S9b, c). The waveforms show complexities resulting from both the undulating CMB (strong variation of SsPmp amplitude; Fig. S9j) and LAB (cf. H1 and H2 as in Figs. 4b, c). This contrasts with the in-phase cancellation effects shown in the 1200 and $600 \mathrm{~km}$-wavelength cases because at short structure wavelengths the refraction points of the obliquely incident $\mathrm{S}$ rays at the $\mathrm{CMB}$ and the $\mathrm{LAB}$ are at very different locations, preventing in-phase cancellations. Despite the extremely complicated SsPmp waveforms and the generally weak, sometimes even invisible, SsPmp (Figs. S9b, c, j), our back- 
In review with Geophysical Journal International

projection method still yields the correct Moho depths for the CMB valleys (Figs. S9e, i) due to the high SsPmp amplitude of the traces reflected at those locations (e.g. green trace in Fig. S9j).

\subsection{Effects of sedimentary basins}

It is widely known that sedimentary basins have significant effects on the waveforms of receiver functions, which has motivated considerable to quantify and alleviate these effects (e.g. Langston, 2011; Tao et al., 2014; Yu et al., 2015). In contrast, the effects of sedimentary basins on VDSS have largely been unresearched. In Part 1, we showed with 1D waveform modelling that, in addition to introducing extra travel-time delays, sedimentary basins can significantly decrease $A_{V D S S}$ due to the reduced S-to-P reflection coefficients at the virtual sources, thereby posing challenges to measuring $T_{V D S S}$ and $\Phi_{V D S S}$ from $S s P m p$ waveforms. Here, we use 2D synthetic waveforms to assess the effects of lateral variation in basin thickness on SsPmp waveforms and test ability of our back-projection method to recover the Moho depth under these circumstances.

We consider two simple cases of sedimentary basins with moderate $V_{p}, V_{s}$, and density (Fig. 10a) overlying the crystalline crust, a "shallow-basin model" with a $3 \mathrm{~km}$-thick basin and a “deep-basin model” with a 6 km-thick basin (Figs. 10a, g). The depths of the basins are constant across $300 \mathrm{~km}$ and taper to zero on $40 \mathrm{~km}$-long planar ramps on both sides of the basins (Figs. $10 \mathrm{a}, \mathrm{g})$. The dips of the ramps are $\sim 3^{\circ}$ and $\sim 6^{\circ}$ for the shallow- and deep-basin models respectively. To reduce the irregularity of the quadrangular elements in the velocity models so that the SPECFEM2D simulations are numerically stable, we increase the dips of the ramps to $45^{\circ}$ in the $1 \mathrm{~km}$-wide region around the tips of the basins to make them less sharp, which should have only minor, if any, effects on the output waveforms due to the small scales. We keep the $\mathrm{CMB}$ and the LAB (outside the plotting range of Figs. 10a, g) at the constant depths of $40 \mathrm{~km}$ and $120 \mathrm{~km}$ respectively. Material properties of the crust and the mantle, the incident angle and the ray parameter of the initial planar $\mathrm{S}$ wave, and the receiver array with a $10 \mathrm{~km}$ spacing are all the same as in the previous models (Figs. 10a, g).

Figs. $10 \mathrm{~b}$ and $\mathrm{h}$ show the vertical-component seismograms for the shallow- and deepbasin models aligned by the direct $\mathrm{S}$ arrivals, and Figs. 10c and i show the corresponding pseudo-P-component seismograms. The vertical-component seismograms over the basins show broader and slightly advanced $S s$ (Figs. 10b, h) due to the interference of the sedimentary $S p$ that 
In review with Geophysical Journal International

arrives slightly earlier than $S s$, which is clearly visible on the corresponding pseudo-Pcomponent record sections (Figs. 10c, i). The arrival time of $S s P m p$ varies significantly across the profiles (Figs. 10b, c, h, i). At the western edge of both basins, $T_{V D S S}$ first slightly decreases and then significantly increases with distance until it reaches a constant value (Figs. 10b, c, h, i). At the eastern edge of both basins, $T_{V D S S}$ first slightly increases and then gradually decreases to the value atop the basement (Figs. 10b, c, h, i). This variation of $T_{V D S S}$ results from the net effects of the travel time of the Pmp leg of $S s P m p$ ( $T_{r e f}$ in Eqn. 4) and the differential travel time between $S s$ at the virtual source and $S s$ at the recording station ( $\Delta T_{S S}$ in Eqn. 4). At the western edge, where the recording station is on the basin and the virtual source is on the basement, $S s$ at the station is delayed by the basin, which reduces $\Delta T_{S s}$. On the other hand, because one leg of Pmp traverses the low-velocity basin, $T_{r e f}$ is increased. Because $T_{V D S S}$ is the sum of $T_{r e f}$ and $\Delta T_{S s}$ (Eqn. 4) $T_{V D S S}$ decreases only slightly at the western edge of the basin. For the stations further east, both the virtual sources and the stations are on the basins, causing $\Delta T_{S s}$ to return to normal. In contrast, $P m p$ now traverses the basin twice, which further increases $T_{r e f}$, causing a net effect of increased $T_{V D S S}$. At the eastern edge of the basin, the cause for the $T_{V D S S}$ variation is the opposite to the western edge.

$A_{V D S S}$ also varies across the profile, though not as significantly as $T_{V D S S}$ (Figs. 10c, i). From $\sim 980-1400 \mathrm{~km}$, where the stations record virtual sources located on basins, the SsPmp amplitude on the pseudo-P components $\left(A_{V D S S}\right)$ is weaker due to reduced S-to-P reflection coefficients at the virtual sources (Figs. 10c, i; see Part 1). We measure $A_{V D S S}$ from the pseudo-P components, not vertical components, because SsPmp amplitude variation on vertical components can result from changed particle-motion due to change in near-surface velocities. For instance, SSPmp amplitude on the vertical components significantly increases with distance at the western boundary of the basins, which is not observed on the pseudo-P components (Figs. $10 \mathrm{~b}, \mathrm{c}, \mathrm{h}, \mathrm{i})$ because the $\mathrm{P}$-wave particle-motion direction at the free surface becomes closer to vertical as near-surface velocity decreases. In addition, scattering waves generated at the boundaries of the basins with significantly slower apparent velocities than Ss and SsPmp also interfere with SsPmp and affect $A_{V D S S}$ (Figs. 10b, c, h, i). The scattering waves are stronger in the deep-basin model presumably due to its steeper basin boundaries (Figs. 10b, c, h, i).

Both the theoretical and apparent $p_{S s}$ are constant across the profile except at the basin boundaries where the incident $\mathrm{S}$ wave fronts are locally distorted by the dipping basin-basement 
In review with Geophysical Journal International

interfaces (Figs 10d, j). As in our previous examples, the apparent $p_{S s}$ shows weaker variation than the theoretical $p_{S s}$ due to finite frequency effects (Figs $10 \mathrm{~d}, \mathrm{j}$ ). The apparent $\Phi_{V D S S}$ is lower atop the basins and shows strong local variations (Figs, 10e, $\mathrm{k}$ ). The lower apparent $\Phi_{V D S S}$ is likely due to the interference of SSPmp and its sedimentary multiples that arrive right after it, while the local variations are probably due to the interferences of basin-boundary-scattering waves.

We apply our back-projection procedure to the synthetic waveforms and produce the images in Figs 10f and 1. The Moho depth discrepancies in the images are approximately symmetrical about the center of the basin (Figs. 10f, 1) in contrast to the asymmetrical spatial pattern of $T_{V D S S}$ in the record sections (Figs. 10b, c, h, i) because our back-projection procedure correctly accounts for the effects caused by lateral variation of the $S s$ arrival time. The imaged Moho is deeper than the true CMB below the basins primarily because our back-projection procedure uses a constant crustal $V_{p}^{a v}$ of $6.5 \mathrm{~km} / \mathrm{s}$, ignoring the low-velocity basins. The Moho

depths calculated from $T_{V D S S}$ measured in the center of the basins, but using $V_{p}{ }^{a v}=6.5 \mathrm{~km} / \mathrm{s}$, are 43 and $46 \mathrm{~km}$ for the shallow- and deep-basin models respectively (dashed lines in Figs. 10f, 1), similar to the average imaged Moho depth beneath the basins (Figs. 10f, 1). The parts of the imaged Moho that are deeper than 43 and $46 \mathrm{~km}$ in the two cases are likely due to the interference of basin-boundary-scattering waves with SsPmp (Figs. 10f, 1). A future development, though beyond the scope of this paper, would be a back-projection scheme that accounts for lateral variations of average crustal $V_{p}$ to correctly image the CMB geometry. We note that if we further reduce the velocities in the basins or introduce internal basin layering, $A_{V D S S}$ of traces with their virtual sources in the basins will further decrease (Part 1), and the basin-boundary-scattering waves will be stronger, both posing additional challenges to our backprojection procedure.

\section{APPLICATION TO THE ORDOS BLOCK}

The Ordos Block in northern China (Fig. 11b) is of considerable interest, as it is the remnant of the Archean North China Craton (Liu et al., 1992) beneath a sedimentary basin $\sim 5$ $\mathrm{km}$ thick (e.g. Xia et al., 2017). It is still debated why this region preserved its lithospheric root while the eastern part of the craton underwent significant modification (decratonization) during the Mesozoic (Gao et al., 2008; Menzies et al., 1993). The Ordos Block is expected to hold 
In review with Geophysical Journal International

important clues for cratonic evolution, thus having been the subject of numerous previous studies. However, to date contradicting results have been reported regarding the crustal thickness of the Ordos Block. The studies using only receiver-function (RF) methods agree on a moderate crustal thickness of 40-45 km (including the sedimentary basin) (Feng et al., 2017; Tian et al., 2011; Wang et al., 2014) [with the exception of He et al. (2018) who showed quite different RF images and inferred a thicker crust]. On the other hand, using VDSS, Yu et al. (2012) found that the crustal thickness close to the eastern margin of the Ordos Block is $\sim 60 \mathrm{~km}$, significantly larger than the values given by RF methods. Yu et al. (2012) interpreted the layer between the RF Moho at $40 \mathrm{~km}$ and the VDSS Moho at $60 \mathrm{~km}$ depth as a mafic lower-crustal layer that has survived since the formation of the North China Craton. However, strong lateral variation of LAB depth is present below the eastern boundary of the Ordos block (Chen et al., 2009; Guo et al., 2016), likely having significant effects on the VDSS Moho depth given by Yu et al. (2012) (Part 1; Yu et al., 2016). Because the west-east linear array of seismic stations used by Yu et al. (2012) (gray triangles in Fig. 11b) recorded no earthquakes suitable for VDSS analyses in line with the recording array we cannot use this dataset to quantify the lateral variation in lithospheric structure and use it to correct our VDSS Moho images. ChinArray, an ongoing project with the ultimate goal of covering China with a dense broadband seismic network, was active in northern China from 2016-2017, which enabled the simultaneous recording of a single event on stations that cover most of the Ordos Block and the adjacent regions (Fig. 11). We use this dataset to demonstrate the application of our back-projection methods to real data and to quantify and remove the previously misleading effects of lateral variations in lithospheric structures on VDSS Moho depth.

Among all the events in the epicentral distance range of $40-60^{\circ}$ recorded by the Ordos segment of the ChinArray, Event 2017-03-21, a M5.6 event with a focal depth of $111.7 \mathrm{~km}$ (Fig. 11a) was recorded by the most stations (Fig. 11b) and had a short source time function (Fig. 12d) that facilitates our analysis. We first filtered all the traces of this event between $0.05-0.5 \mathrm{~Hz}$ and used the Crazyseismic software package (Yu et al., 2017) to manually pick the records with clear Ss and SsPmp arrivals. We separated the picked traces into pseudo-P and pseudo-S components using our particle-motion analysis algorithm (Yu et al., 2013). We assumed that the separated pseudo-S-component records only contain Ss arrivals and used MCCC to align them, yielding the Ss travel time residuals with respect to the AK135 earth model (Kennett et al., 1995) at the 
In review with Geophysical Journal International

recording stations (Fig. 11b). We stacked the pseudo-S-component seismograms to estimate the source time function and shifted all the traces so that the positive peak on the source time function is at time zero. This process guarantees the correct reference value for measuring $T_{V D S S}$. We did not align the traces to the peaks of the envelope functions of the pseudo-S components as we did for our synthetic examples because in our field data the source time function is no longer perfectly antisymmetric so that after a $90^{\circ}$ phase shift the wavelet would become asymmetric with its peak not at time zero. We instead aligned all traces to the peaks of the pseudo-S components themselves, correct all the pseudo-P components (assumed to contain only SsPmp) to $0^{\circ}$ phase shift, and pick the peaks on the back-projection images as the Moho depths (with results described in detail later in this section). On our travel-time-residual map, we observe a clear clustering of negative residuals (early arrivals) in the northern Ordos Block and positive residuals (late arrivals) in the Weihe Graben and Shanxi Graben (Fig. 11b). The negative residuals cluster in the northern Ordos Block, not the center, because the seismic rays come from the south and project the footprint of the thick and fast lithospheric root beneath the central Ordos Block to the north of it. We then chose a trajectory from Event 2017-03-21 that traverses a dense corridor of stations. For all stations within $30 \mathrm{~km}$ of the trajectory we use the coordinates of their projections onto the trajectory as their new coordinates on our 1D linear array (Fig. 11b). We truncate our profile at $\sim 39^{\circ} \mathrm{N}$ due to the increasing multiples generated by the low-velocity sedimentary layer that covers most of the northern Ordos Block (Wang et al., 2014). Because our event is from similar back azimuths and epicentral distances as the events used in Yu et al. (2012) (Fig. 11a) our profile crosses the area where Yu et al. (2012) found the overthickened crust (black oval in Fig. 11b), offering a chance for direct comparison between the two studies. The northward decrease of the Ss travel-time residuals (Figs. 11b, 12b) highlights the need to account for lateral variations in lithospheric structures. In order to make the travel-time residuals and the ray parameters smooth functions of distance, we use a third-degree polynomial to fit the residuals (Fig. 12b). We then take the spatial derivative of the travel-time residuals and add it to the ray parameters predicted by the AK135 model to derive the observed ray parameters (Fig. 12c), which have a significantly wider variation than the predicted ray parameters (Fig. 12c). The wide range of observed ray parameter also corresponds to a wide range of turning velocity, from $\sim 7.2 \mathrm{~km} / \mathrm{s}$ in the south to $\sim 8.4 \mathrm{~km} / \mathrm{s}$ in the north (Fig. 12c). 
In review with Geophysical Journal International

We observe similar clear $S s$ arrivals on the pseudo-S-component seismograms across different stations (Fig. 12d). On the pseudo-P-component seismograms, $T_{V D S S}$ increases significantly northward from the Weihe Graben $(\sim 5 \mathrm{~s})$ to the central Ordos Block $(\sim 10 \mathrm{~s})$ (Fig.12e). Using Eqn. 6 with an average crustal $V_{p}=6.2 \mathrm{~km} / \mathrm{s}$ and a ray parameter $p=0.13 \mathrm{~s} / \mathrm{km}$, the observed variation in $T_{V D S S}$ corresponds to a change of crustal thickness from $\sim 26 \mathrm{~km}$ beneath the Weihe Graben to $\sim 52 \mathrm{~km}$ beneath the central Ordos Block, significantly greater than the variation shown by RF methods (30-45 km; Figs. 12g, h) (Feng et al., 2017; Wang et al., 2014). The apparent greater variation in VDSS Moho depth results from the lateral variation of both the $S s$ travel-time residuals and ray parameters (Figs. 12b, c). To properly address this problem, we apply our back-projection method (section 2.1.2) to the pseudo-P-component seismograms. First, we measure $\Phi_{V D S S}$ on each trace along the profile (diamonds in Fig. 12f) and find a clear decreasing trend. This observation is important because, by contrast, a flat CMB would cause an increasing $\Phi_{V D S S}$ with a decreasing ray parameter along the profile (Part 1). Two factors may cause the decrease of $\Phi_{V D S S}$ with distance. First, as will be shown later, the CMB deepens northward along the profile, a situation modelled in our synthetic with a $600 \mathrm{~km}-$ wavelength $\mathrm{CMB}$ and a flat LAB, where the apparent $\Phi_{V D S S}$ decreases from $\sim 160^{\circ}$ to $\sim 30^{\circ}$ as distance increases from $\sim 1100-1300 \mathrm{~km}$ (Figs. 6a, e). Second, because the sedimentary layer above the Ordos Block becomes thicker and probably has lower velocities northward along our profile (Wang et al., 2014) the sedimentary layer has stronger effects on the SsPmp waveforms in the north than in the south, which might manifest itself as a further decrease in the observed $\Phi_{V D S S}$ (Part 1; Figs. 10e, k). Before applying our phase-shift correction, we discarded two measurements of $\Phi_{V D S S}=180^{\circ}$ that we suspect are erroneous (gray diamonds in Fig. 12f) and interpolated $\Phi_{V D S S}$ as a function of distance using a second-degree polynomial (red curve in Fig. $12 \mathrm{f})$. Because the $S s$ arrivals are aligned by their positive peaks we used the fitted $\Phi_{V D S S}$ as a function of distance to correct the phase shift of each pseudo-P-component trace to $0^{\circ}$ so that $T_{V D S S}$ of each trace is at the positive peak. To address the uneven station distribution in this real dataset, we interpolated the pseudo-P-component traces to $10 \mathrm{~km}$ bins. We then used $V_{p}{ }^{a v}=6.2$ $\mathrm{km} / \mathrm{s}$ (including sedimentary layers, Xia et al., 2017), to back project the phase-shift-corrected and interpolated pseudo-P-component traces. Our data-processing workflow, from wave-mode separation to back projection, is summarized in Fig. 13. 
In review with Geophysical Journal International

We picked the Moho depths at the maximum positive amplitude for each location because the phase shift of each input trace was corrected to $0^{\circ}$. We compute two back-projection images, one with zero travel-time residual and the AK135-predicted ray parameter ("uncorrected" Moho-depth picks, black dotted curves in Figs. 12g and h), and the other using the observed travel-time residual and ray parameter ("corrected" Moho-depth picks, black solid curves in Fig. 12h) so that the effects of the lateral variation in the lithospheric structure can be identified. For comparison, we project the RF Moho depths given by Feng et al. (2017) on stations within $30 \mathrm{~km}$ of our profile and plot them on the two back-projection images (yellow circles in Figs. 12g, h). We also plot the approximate depth of the bottom of the relaminated "growth zone" in the range where such a layer is identified by He et al. (2018) (yellow dotted lines in Figs. 12g, h). We did not plot the RF Moho depths from Wang et al. (2014) because their stations are too sparse along our profile. Because our back-projection requires known $p_{S s}$ at both the virtual source and the receiver, our corrected back-projection image only gives reliable results in the range 180-450 $\mathrm{km}$ (hereafter the profile), which includes the transition from the Weihe Graben to the Ordos Block (Figs. 12g, h). On the uncorrected image, the Moho starts at $\sim 30 \mathrm{~km}$ depth beneath the Qinling Mountains south of the Ordos Block and gradually deepens northward, reaching $\sim 56 \mathrm{~km}$ depth in the central Ordos Block (Fig. 12g). This VDSS Moho depth is significantly deeper than the RF Moho estimates (yellow circles and yellow dashed line in Fig. 12g) but similar to the VDSS Moho from Yu et al. (2012) (gray diamonds in Fig. 12g) as expected because neither our uncorrected Moho image nor Yu et al. (2012) accounted for lateral variation in lithospheric structure. In contrast, our corrected image shows the VDSS Moho depth consistent with the RF Moho from 180-300 km, then gradually deepening northward to $\sim 50 \mathrm{~km}$ at the northern end of the profile (Fig. 12h). Our VDSS Moho has a much lower dip after correction because the effects of the $S s$ travel time variation have been removed (Fig. 12h). The discrepancy between the VDSS Moho and the RF Moho decreases significantly after correction, and our corrected VDSS Moho now matches the RF Moho at the bottom of the "growth zone" (yellow dashed line in Fig. 12h; He et al. 2018) beneath the central Ordos Block (Fig. 12h). This example with real data shows that our back-projection method using observed travel-time residuals and ray parameters significantly improves VDSS Moho depth estimates in regions with significant lateral variation in lithospheric structure. 
In review with Geophysical Journal International

We conduct additional tests to explore possible reasons for the discrepancy between our corrected VDSS Moho depth and the RF Moho depth from Feng et al. (2017). Fig. 14b shows the corrected VDSS Moho computed with $V_{p}{ }^{a v}=6.0 \mathrm{~km} / \mathrm{s}$ (gray dotted curve in Fig. 14b), which is significantly shallower than the one calculated with average crustal $V_{p}{ }^{a v}=6.2 \mathrm{~km} / \mathrm{s}$ and in better agreement with the Feng et al. (2017) RF Moho in the segment beyond $300 \mathrm{~km}$ (Fig. 14d). Since the sedimentary layer in the Ordos Block thickens towards the interior of the block (Yang et al., 2005), the northern part of our profile might indeed have a lower $V_{p}{ }^{a v}$ than the southern part. This effect is also clearly shown in our synthetic examples with sedimentary layers (Figs. 10f, 1). Our observed decrease of $\Phi_{V D S S}$ with distance (Fig. 12f) appears to conflict with the decrease of ray parameters with distance (Fig. 12c), raising the possibility that observed $\Phi_{V D S S}$ might be inaccurate, in which case our phase-shift correction would be wrong. To test this hypothesis, we apply a $-90^{\circ}$-phase-shift correction to all the pseudo-P-component traces, which is equivalent to assuming all traces to have $\Phi_{V D S S}=90^{\circ}$. We choose $90^{\circ}$ because the traces with the highest $A_{V D S S}\left(\right.$ Fig. 12e), thus likely the most robust $\Phi_{V D S S}$ measurements have $\Phi_{V D S S}=\sim 90^{\circ}$ at $\sim 250 \mathrm{~km}$ (Fig. 12f). Applying our back-projection method to these phase-shift-corrected traces with $V_{p}{ }^{a v}=6.2 \mathrm{~km} / \mathrm{s}$ produces an image with a significantly flatter Moho and a better agreement with the RF Moho depths from Feng et al. (2017) (solid gray curve in Figs. 14c and d). This better agreement does not necessarily indicate that the $-90^{\circ}$-phase-shift correction is superior to the correction method using variable $\Phi_{V D S S}$ because the RF Moho depths themselves might have large uncertainties. The main goal for this test with $-90^{\circ}$-phase-shift correction is to quantify the potential uncertainties (up to $10 \mathrm{~km}$; Fig. 14d) that could be due to inappropriately correcting for SsPmp phase shifts in our back-projection process.

We identify four additional possible reasons for the discrepancy between our corrected VDSS Moho and the RF Moho from Feng et al. (2017). First, we have shown with our synthetic tests that our back-projection method might be insufficient to correct the effects of $S s$ travel time variations, particularly when lateral heterogeneity is strong (i.e. Figs. 4, 8, and 9). In our Ordos case, although the crust thickens northward along the profile (Figs. 12g, h), the dramatic northward decrease of the $S s$ travel-time residuals indicates that the northward thickening of lithosphere (deepening of the LAB) has the dominant effect (Fig. 12b). In our synthetic cases where LAB depth changes dominate $S s$ travel-time variations (e.g. Figs. 3, 4), and the deepening LAB causes an increased Moho depth in the uncorrected back-projection image (e.g. 1100-1300 
km in Fig. 4k), the corrected Moho depth also remains slightly deeper than the true CMB depth. In our synthetic example with a $400 \mathrm{~km}$-wavelength $\mathrm{LAB}$ and a flat CMB, the range of the $S s$ travel-time residuals is $\sim 1 \mathrm{~s}$, and the remnant discrepancy between the corrected VDSS Moho depth and the true CMB depth is $\sim 2 \mathrm{~km}$ (Fig 4k). Because in our Ordos case the range of the $S s$ travel time residual is $\sim 2.5 \mathrm{~s}$, a simple scaling suggests a remnant discrepancy between our corrected VDSS Moho depth and the true CMB depth of $\sim 5 \mathrm{~km}$, which could explain most of the discrepancy between our VDSS Moho and the Feng et al. (2017) RF Moho (Fig. 12h). Second, our VDSS Moho might not represent the true CMB in this region. Because the SsPmp turning velocity is $>8.33 \mathrm{~km} / \mathrm{s}$ for most of the range beyond $250 \mathrm{~km}$ (Fig. 12c), higher than the $P n$ velocity given by the active-source studies in this region $(\sim 8.3 \mathrm{~km} / \mathrm{s})$ (Jia et al., 2014), $S s P m p$ waves might become refractions in the upper mantle due to their high turning velocity. This phenomenon would cause an apparently deeper VDSS Moho because the upper mantle above the SsPmp turning depth would also be included in the crustal depth estimation (for more discussion of this possibility see Part 2). Third, the Moho found by Feng et al. (2017) may not represent the true CMB in this region. As shown in He et al. (2018), a "growth zone" with $V_{p}=6.2-7.5 \mathrm{~km} / \mathrm{s}$ extending down to $\sim 50 \mathrm{~km}$ depth might exist beneath the north-central Ordos Block (yellow dashed line in Fig. 12g, h). If this interpretation is true, our VDSS Moho will represent the true CMB, whereas Feng et al. (2017) might have identified an intra-crustal interface, possibly the top of the "growth zone", as the CMB. Fourth, the published RF Moho depths typically ignore significant heuristic uncertainty in their choices of $V_{p}{ }^{a v}$ and multiple-stacking weights, again allowing the possibility that our VDSS Moho marks the true CMB and the RF Moho is in error. We do not believe it is possible to distinguish between these possibilities at present and suggest that the Ordos Block has a crustal thickness of $45 \pm 5 \mathrm{~km}$, including $\sim 5 \mathrm{~km}$ of Phanerozoic sedimentary basin.

\section{DISCUSSION AND CONCLUSIONS}

Post-critical SsPmp has three major attributes: $T_{V D S S}, \Phi_{V D S S}$, and $A_{V D S S}$. An outstanding question about $S s P m p$ waveforms in $2 \mathrm{D}$ is to what extent these attributes can be modeled with the ray theory. With our synthetic examples, we show that variations of $A_{V D S S}$ can be qualitatively explained with $S s P m p$ ray density and with amplitude-with-angle variation that largely depends on whether the ray undergoes pre-critical or post-critical reflection at the CMB. 
In review with Geophysical Journal International

Specifically, a rapid lateral change of $A_{V D S S}$ is a useful diagnostic for CMB depth variations (e.g. Fig. 8) because velocity changes below the CMB that cause similar $T_{V D S S}$ variations produce a smaller change in $A_{V D S S}$ (compare Fig. 4c, m with Fig. 8c, k). Therefore, future work might usefully incorporate $A_{V D S S}$ into constraining CMB topography. However, extra care must be taken when analyzing $A_{V D S S}$ because in field observations the effects of CMB variations on $A_{V D S S}$ are usually combined with the effects of sedimentary layers and can only be distinguished using array data and/or prior knowledge of sedimentary-basin geometry (Part1; Fig. 10). Modeling $\Phi_{V D S S}$ with the ray theory is largely unsuccessful except in cases with very smoothly varying LAB topography $\left(\lambda>1200 \mathrm{~km}\right.$ ) because ray-theory predictions of $\Phi_{V D S S}$ implicitly assume a planar down-going $\mathrm{P}$ wave incident at the $\mathrm{CMB}$, which is invalid when $S s$ at the free surface is significantly non-planar (e.g. Figs. 3 and 4). In addition, a curved CMB further distorts the $S s P m p$ wave front from the assumed planar reflected wave (e.g. Fig. 5). Therefore, inferring $V_{p}^{u m}$ from $\Phi_{V D S S}$ in the presence of significant lateral heterogeneity requires methods to properly model non-planar-wave behavior of SSPmp without the need for expensive numeric simulations. A possible solution and direction for future research is to use the Kirchhoff Theory to model a curved wave front and its interactions with curved interfaces (Shearer, 1999).

In contrast to $A_{V D S S}$ and $\Phi_{V D S S}, T_{V D S S}$ can be quantitatively modeled with ray theory in a heterogeneous lithosphere, as evidenced by the success of our back-projection method. In general, we find SsPmp amplitude a useful diagnostic for the reliability of back-projection images. Our synthetic tests show that in most cases where SsPmp can be reliably observed (with strong amplitude), our back-projection procedure is capable of imaging the CMB reasonably well. This degree of success is exciting because it has been achieved despite the assumption of a flat Moho in our back-projection method. An iterative process using our result as the basis for calculating an updated Moho image should in theory yield further improvements. Oher seismic methods that use reverberations of teleseismic body waves to image Earth's deep structures (e.g. Shearer and Buehler, 2019) likely face similar problems as VDSS. Therefore, our backprojection method may have broader applications in global seismology.

\section{Acknowledgements:}

Tianze Liu is supported by a Stanford Graduate Fellowship. We thank Steve Roecker and Greg Beroza for their valuable suggestions. We thank Yi Wang for help with SPECFEM2D and 
In review with Geophysical Journal International

Wei Wang for help with the f-k program generously provided by Lupei Zhu. We thank Robyn Brinks Lockwood for improving the language of this paper. The 2D synthetic waveforms were calculated using SPECFEM2D, generously made available by Dimitri Komatitsch, who provided much guidance before his recent and sudden death.

\section{References:}

Aki, K., Richards, P.G., 2002. Reflection and transmission of P-SV across a solid-solid interface, in: Ellis, J. (Ed.), Quantitative Seismology (2nd Edition). University Science Books, pp. $139-145$.

Buehler, J.S., Shearer, P.M., 2017. Uppermost mantle seismic velocity structure beneath USArray. J. Geophys. Res. Solid Earth 122, 436-448.

https://doi.org/10.1002/2016JB013265

Chen, L., Cheng, C., Wei, Z., 2009. Seismic evidence for significant lateral variations in lithospheric thickness beneath the central and western North China Craton. Earth Planet. Sci. Lett. 286, 171-183. https://doi.org/10.1016/j.eps1.2009.06.022

Feng, M., An, M., Dong, S., 2017. Tectonic history of the Ordos Block and Qinling Orogen inferred from crustal thickness. Geophys. J. Int. 210, 303-320. https://doi.org/10.1093/gji/ggx163

Fischer, K.M., Ford, H.A., Abt, D.L., Rychert, C.A., 2010. The Lithosphere-Asthenosphere Boundary. Annu. Rev. Earth Planet. Sci. 38, 551-575. https://doi.org/10.1146/annurevearth-040809-152438

Fliedner, M.M., Ruppert, S., Southern Sierra Nevada Continental Dynamic Working Group, 1996. Three-dimensional crustal structure of the southern Sierra Nevada from seismic fan profiles and gravity modeling. Geology 24, 367-370.

Gao, S., Rudnick, R.L., Xu, W.L., Yuan, H.L., Liu, Y.S., Walker, R.J., Puchtel, I.S., Liu, X., Huang, H., Wang, X.R., Yang, J., 2008. Recycling deep cratonic lithosphere and generation of intraplate magmatism in the North China Craton. Earth Planet. Sci. Lett. 270, 41-53. https://doi.org/10.1016/j.eps1.2008.03.008

Guo, Z., Afonso, J.C., Qashqai, M.T., Yang, Y., Chen, Y.J., 2016. Thermochemical structure of the North China Craton from multi-observable probabilistic inversion: Extent and causes of 
In review with Geophysical Journal International

cratonic lithosphere modification. Gondwana Res. 37, 252-265.

https://doi.org/10.1016/j.gr.2016.07.002

He, Y., Zheng, T., Ai, Y., Hou, G., Chen, Q.F., 2018. Growth of the lower continental crust via the relamination of arc magma. Tectonophysics 724-725, 42-50. https://doi.org/10.1016/j.tecto.2018.01.006

Hopper, E., Fischer, K.M., 2018. The Changing Face of the Lithosphere-Asthenosphere Boundary: Imaging Continental Scale Patterns in Upper Mantle Structure Across the Contiguous U.S. With Sp Converted Waves. Geochemistry, Geophys. Geosystems 19, 2593-2614. https://doi.org/10.1029/2018GC007476

Jia, S., Wang, F., Tian, X., Duan, Y., Zhang, J., Liu, B., Lin, J., 2014. Crustal structure and tectonic study of North China Craton from a long deep seismic sounding profile. Tectonophysics 627, 48-56. https://doi.org/10.1016/j.tecto.2014.04.013

Kang, D., Yu, C., Ning, J., Chen, W., 2016. Simultaneous Determination of Crustal Thickness and $P$ Wavespeed by Virtual Deep Seismic Sounding (VDSS). Seismol. Res. Lett. 87, 1104-1111. https://doi.org/10.1785/0220160056

Kennett, B.L.N., Engdahl, E.R., Buland, R., 1995. Constraints on seismic velocities in the Earth from traveltimes. Geophys. J. Int. 122, 108-124. https://doi.org/10.1111/j.1365246X.1995.tb03540.x

Klemperer, S.L., Hauge, T.A., H, E.C., Oliver, J.E., Potter, C.J., 1986. The Moho in the northern Basin and Range province, Nevada, along the COCORP 40 \{degrees $\} \mathrm{N}$ seismic-reflection transect. Geol. Soc. Am. Bull. 97, 603-618. https://doi.org/10.1130/0016-7606(1986)97

Komatitsch, D., Martin, R., Tromp, J., Taylor, M.A., Wingate, B.A., 2001. Wave propagation in 2-D elastic media using a spectral element method with triangles and quadrangles. J. Comput. Acoust. 9, 703-718. https://doi.org/10.1142/S0218396X01000796

Komatitsch, D., Vilotte, J.-P., 1998. The Spectral Element Method : An Efficient Tool to Simulate the Seismic Response of 2D and 3D Geological Structures. Bull. Seismol. Soc. Am. 88, 368-392.

Langston, C.A., 2011. Wave-field continuation and decomposition for passive seismic imaging under deep unconsolidated sediments. Bull. Seismol. Soc. Am. 101, 2176-2190. https://doi.org/10.1785/0120100299

Liu, D.Y., Nutman, A.P., Compston, W., Wu, J.S., Shen, Q.H., 1992. Remnants of Greater- 
In review with Geophysical Journal International

Than-or-Equal-to 3800 Ma Crust in the Chinese Part of the Sino-Korean Craton. Geology 20, 339-342. https://doi.org/10.1130/0091-7613(1992)020<0339:romcit $>2.3 . c o ; 2$

Liu, T., Klemperer, S.L., Ferragut, G., Yu, C., 2019. Post-critical SsPmp and its applications to Virtual Deep Seismic Sounding (VDSS) - 2: 1-D imaging of the crust/mantle and joint constraints with receiver functions. Geophys. J. Int. 219, 1334-1347. https://doi.org/10.1093/gji/ggz370

Liu, T., Klemperer, S.L., Yu, C., Ning, J., 2018. Post-critical SsPmp and its applications to Virtual Deep Seismic Sounding (VDSS) - 1: sensitivity to lithospheric 1-D and 2-D structure. Geophys. J. Int. 215, 880-894. https://doi.org/10.1093/gji/ggy307

Luo, S., Zhu, L., Huang, R., Luo, Y., Jiang, X., Hua, Y., 2018. Determination of crustal thickness and velocities by using receiver functions and PmP travel times . Geophys. J. Int. 216, 1304-1312. https://doi.org/10.1093/gji/ggy500

Menzies, M. a., Fan, W., Zhang, M., 1993. Palaeozoic and Cenozoic lithoprobes and the loss of $>120 \mathrm{~km}$ of Archaean lithosphere, Sino-Korean craton, China. Geol. Soc. London, Spec. Publ. 76, 71-81. https://doi.org/10.1144/GSL.SP.1993.076.01.04

Parker, E.H., Hawman, R.B., Fischer, K.M., Wagner, L.S., 2016. Estimating crustal thickness using SsPmp in regions covered by low-velocity sediments: Imaging the Moho beneath the Southeastern Suture of the Appalachian Margin Experiment (SESAME) array, SE Atlantic Coastal Plain. Geophys. Res. Lett. 43, 9627-9635. https://doi.org/10.1002/2016GL070103 Shearer, P.M., 1999. Kirchoff Theory, in: Introduction to Seismology. pp. 133-138.

Shearer, P.M., Buehler, J., 2019. Imaging Upper-Mantle Structure Under USArray Using LongPeriod Reflection Seismology. J. Geophys. Res. Solid Earth 1-15. https://doi.org/10.1029/2019jb017326

Tao, K., Liu, T., Ning, J., Niu, F., 2014. Estimating sedimentary and crustal structure using wavefield continuation: Theory, techniques and applications. Geophys. J. Int. 197, 443-457. https://doi.org/10.1093/gji/ggt515

Thompson, D.A., Rawlinson, N., Tkalčić, H., 2019. Testing the limits of virtual deep seismic sounding via new crustal thickness estimates of the Australian continent. Geophys. J. Int. 787-800. https://doi.org/10.1093/gji/ggz191

Tian, X., Chen, Y., Tseng, T.L., Klemperer, S.L., Thybo, H., Liu, Z., Xu, T., Liang, X., Bai, Z., Zhang, X., Si, S., Sun, C., Lan, H., Wang, E., Teng, J., 2015. Weakly coupled lithospheric 
In review with Geophysical Journal International

extension in southern Tibet. Earth Planet. Sci. Lett. 430, 171-177.

https://doi.org/10.1016/j.epsl.2015.08.025

Tian, X., Teng, J., Zhang, H., Zhang, Z., Zhang, Y., Yang, H., Zhang, K., 2011. Structure of crust and upper mantle beneath the Ordos Block and the Yinshan Mountains revealed by receiver function analysis. Phys. Earth Planet. Inter. 184, 186-193. https://doi.org/10.1016/j.pepi.2010.11.007

Tromp, J., Komatitsch, D., Liu, Q., 2008. Spectral-element and adjoint methods in seismology. Commun. Comput. Phys. 3, 1-32.

Tseng, T.L., Chen, W.P., Nowack, R.L., 2009. Northward thinning of Tibetan crust revealed by virtual seismic profiles. Geophys. Res. Lett. 36, 1-5. https://doi.org/10.1029/2009GL040457

Wang, C.Y., Sandvol, E., Zhu, L., Lou, H., Yao, Z., Luo, X., 2014. Lateral variation of crustal structure in the Ordos block and surrounding regions, North China, and its tectonic implications. Earth Planet. Sci. Lett. 387, 198-211. https://doi.org/10.1016/j.eps1.2013.11.033

Xia, B., Thybo, H., Artemieva, I.M., 2017. Seismic crustal structure of the North China Craton and surrounding area: Synthesis and analysis. J. Geophys. Res. Solid Earth 5181-5207. https://doi.org/10.1002/2016JB013848

Yang, Y., Li, W., Ma, L., 2005. Tectonic and stratigraphic controls of hydrocarbon systems in the Ordos basin: A multicycle cratonic basin in central China. Am. Assoc. Pet. Geol. Bull. 89, 255-269. https://doi.org/10.1360/10070404027

Yu, C., Chen, W.P., van der Hilst, R.D., 2016. Constraints on residual topography and crustal properties in the western United States from virtual deep seismic sounding. J. Geophys. Res. Solid Earth 121, 5917-5930. https://doi.org/10.1002/2016JB013046

Yu, C., Zheng, Y., Shang, X., 2017. Crazyseismic: A MATLAB GUI-Based Software Package for Passive Seismic Data Preprocessing. Seismol. Res. Lett. 88, 410-415. https://doi.org/10.1785/0220160207

Yu, C.Q., Chen, W.P., Ning, J.Y., Tao, K., Tseng, T.L., Fang, X.D., John Chen, Y., van der Hilst, R.D., 2012. Thick crust beneath the Ordos plateau: Implications for instability of the North China craton. Earth Planet. Sci. Lett. 357-358, 366-375. https://doi.org/10.1016/j.epsl.2012.09.027 
In review with Geophysical Journal International

Yu, C.Q., Chen, W.P., Van Der Hilst, R.D., 2013. Removing source-side scattering for virtual deep seismic sounding (VDSS). Geophys. J. Int. 195, 1932-1941. https://doi.org/10.1093/gji/ggt359

Yu, Y., Song, J., Liu, K.H., Gao, S.S., 2015. Determining crustal structure beneath seismic stations overlying a low-velocity sedimentary layer using receiver functions. J. Geophys. Res. B Solid Earth 3208-3218. https://doi.org/10.1002/2014JB011610 
SsPmp ray paths $\quad \sim 60 \mathrm{~km}$

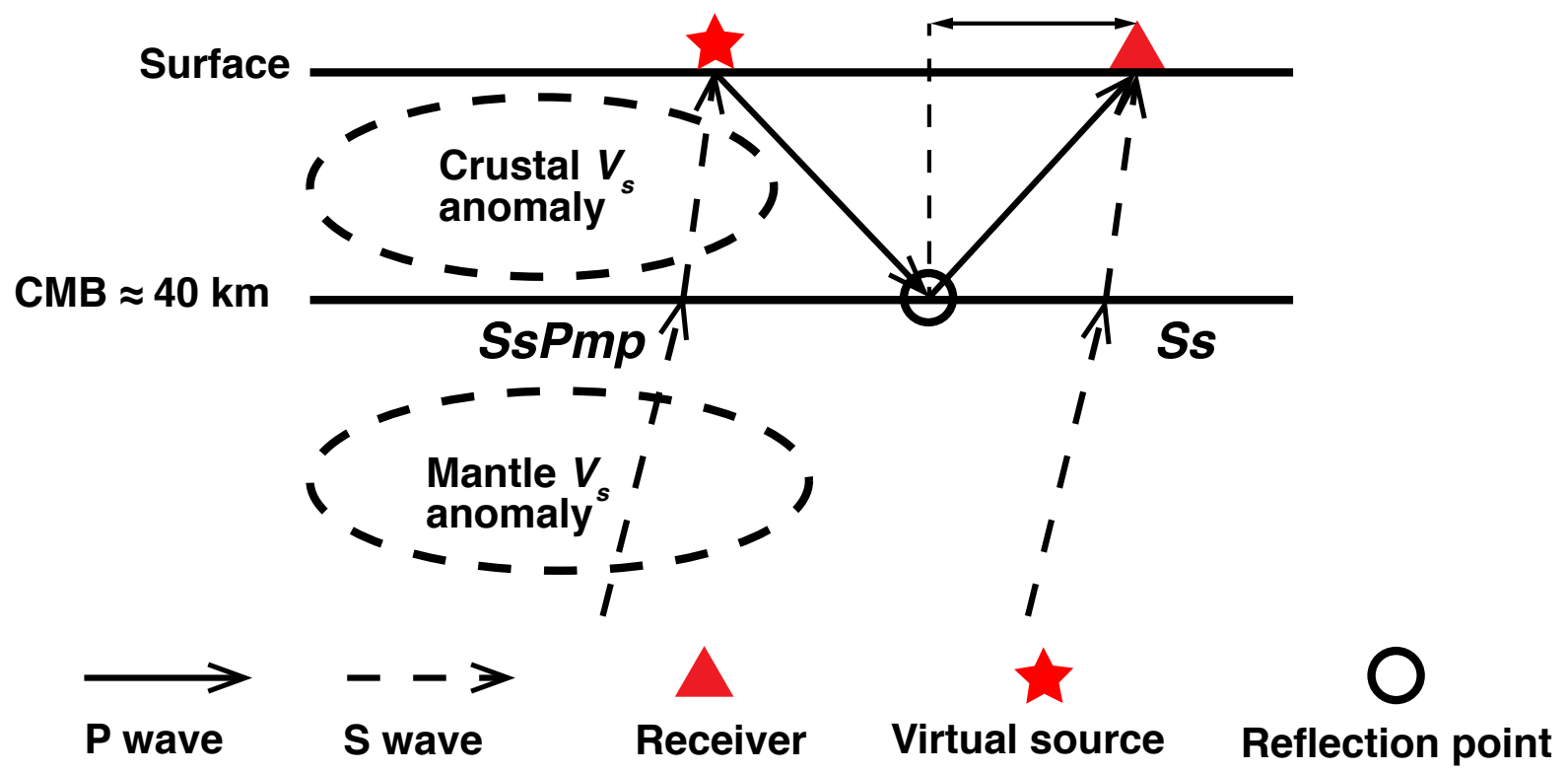

Figure 1. Ray paths of post-critical SsPmp. Note the large separation (>100 km) between virtual source and receiver, making $S s P m p$ sensitive to lateral heterogeneity in the crust and mantle lithosphere. CMB: crust-mantle boundary. 
In review with Geophysical Journal International 
In review with Geophysical Journal International

(a)

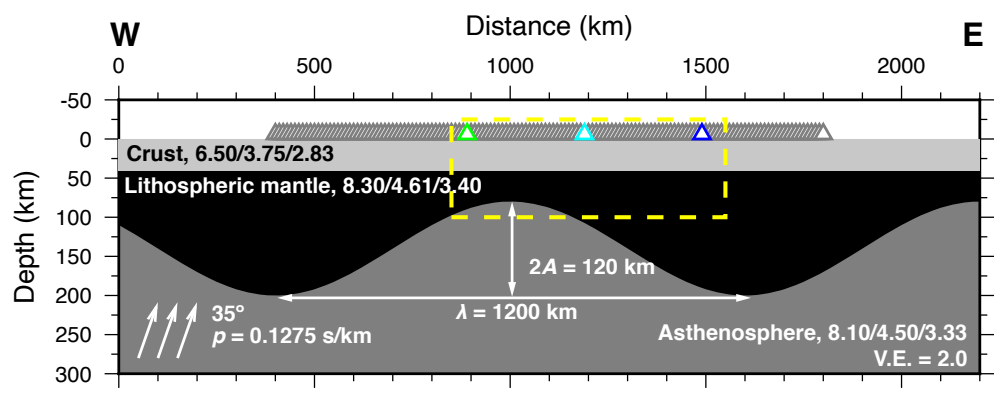

(b)

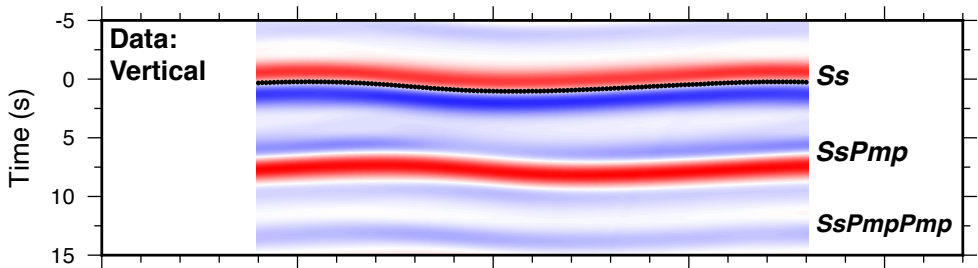

(c)

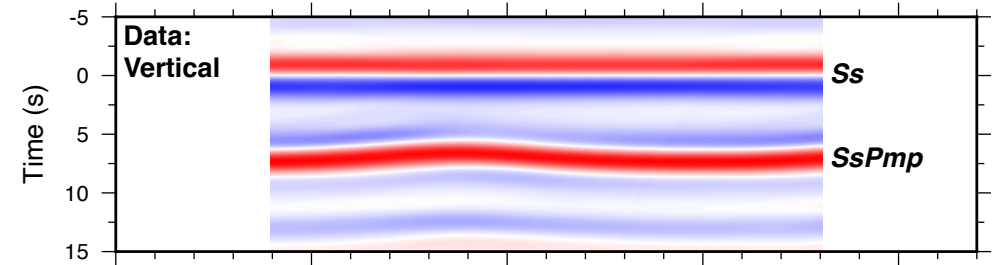

(d)

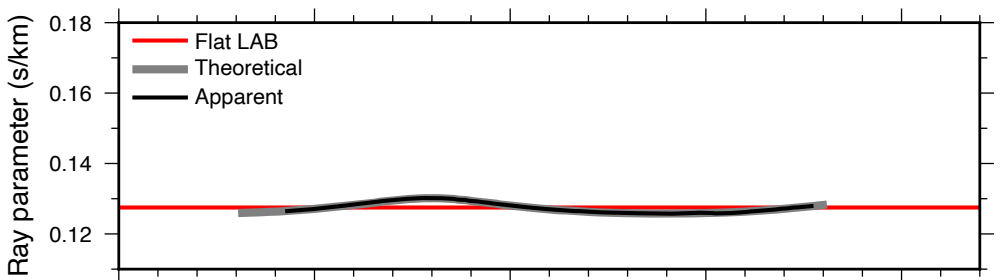

(e)

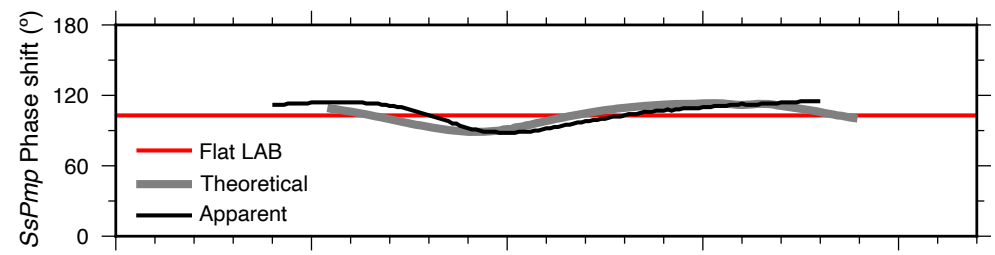

(f)

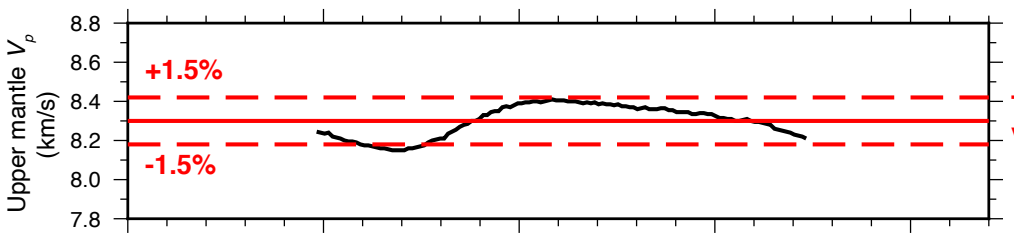

(g)

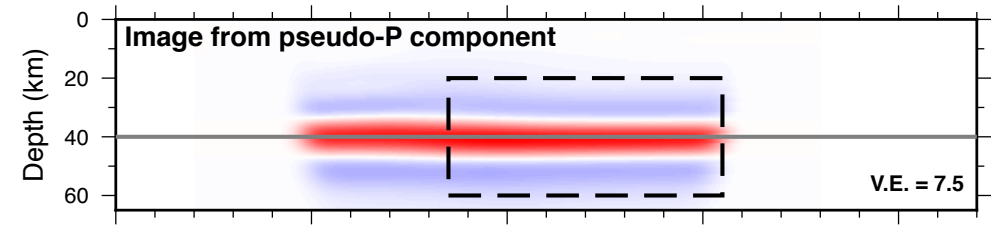

E

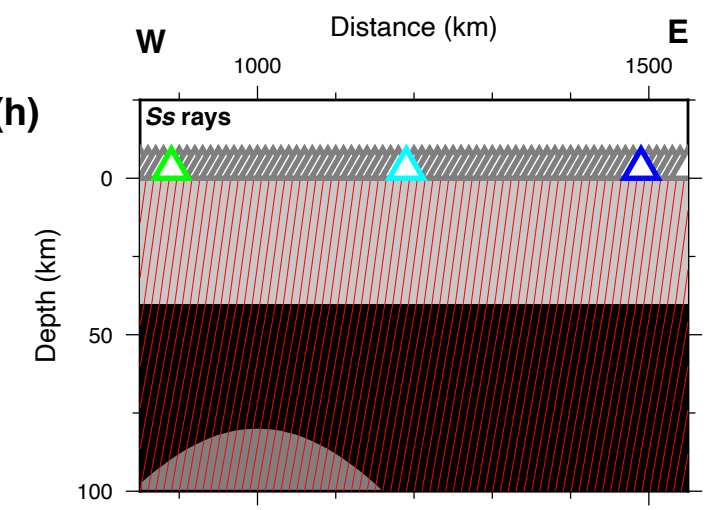

(i)

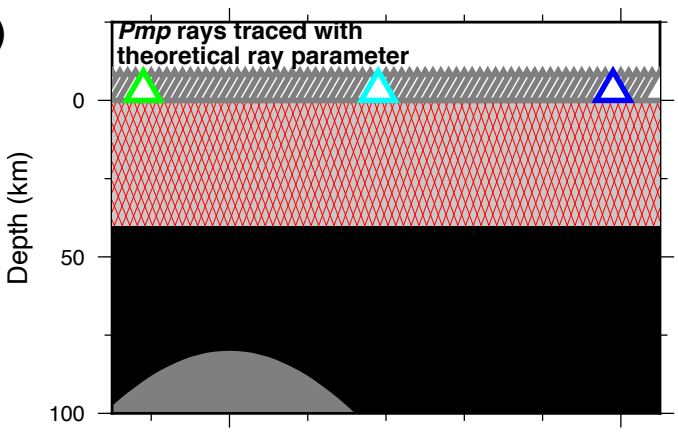

(j)

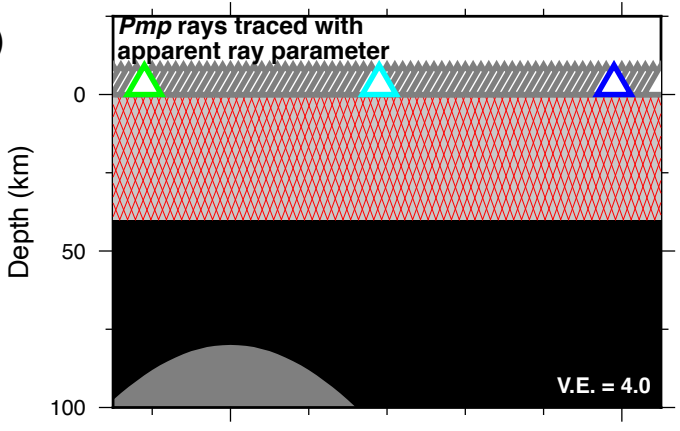

(k)

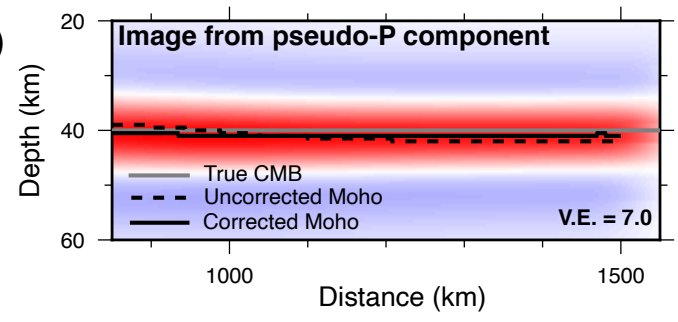

(I)

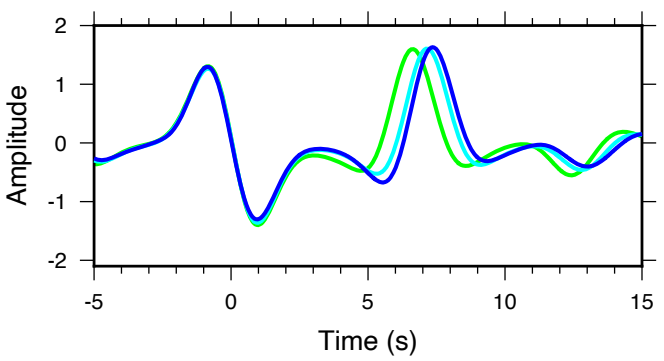


Figure 2. Synthetic test using a sinusoidal LAB with horizontal wavelength of $1200 \mathrm{~km}$, and peak and trough at 80 and $200 \mathrm{~km}$-depth respectively, i.e. $2 \mathrm{~A} / \lambda=0.1, \theta_{a v}=\sim 11^{\circ}$. The $\mathrm{CMB}$ is flat at $40 \mathrm{~km}$ depth. (a) Model setup (vertical exaggeration $\times 2$ ): crust (light gray), lithosphere (black) and asthenosphere (dark gray) are labeled with their $V_{p} / V_{s} /$ density. Triangles are $10 \mathrm{~km}$-spaced seismic stations; green, cyan and blue edges identify stations recording the green, cyan and blue waveforms in (1). Arrows: incident angle of the plane $\mathrm{S}$ wave at the bottom of the model, with the same $\times 2$ vertical exaggeration. Yellow dashed box is area of model enlarged in (h), (i) and (j). (b) Vertical-component synthetic waveforms recorded at each station and aligned to their theoretical $\mathrm{S}$ arrival times predicted with a constant ray parameter $p_{S s}$ of $0.1275 \mathrm{~s} / \mathrm{km}$. Continuous line of black dots: observed S arrival time residuals derived with multi-channel cross-correlation (MCCC). (c) Same as (b), except that the waveforms are aligned to the observed S arrival times given by MCCC. (d) $p_{S S}$ calculated either by ray tracing (theoretical; thick gray curve) or by differentiating $\mathrm{S}$ arrival time with respect to horizontal distance (apparent; thin black curve). The ray parameter $p_{S s}$ applicable to any $S s P m p$ observation is measured at the virtual source point, so is plotted at the trace location where $p_{S s}$ is measured. Apparent $p_{S s}$ can only be measured from an actual recording so is not plotted west of the western trace at $\mathrm{km} 850$ in (b). Red line: $p_{S s}=0.1275 \mathrm{~s} / \mathrm{km}$, i.e. for the equivalent model with a flat LAB. (e) $S s P m p$ phase shifts relative to direct $S s$ ( $\left.\Phi_{V D S S}\right)$ either computed for each traced $S_{s} P m p$ ray assuming a plane incident wave (theoretical; gray curve) or measured from pseudo-P-component synthetic waveforms (apparent; black curve). Red line: $\Phi_{V D S S}$ for the equivalent model with a flat LAB. (f) Black curve: upper-mantle $V_{p}^{u m}$ measured from apparent $\Phi_{V D S S}$ assuming a plane wave incident at the CMB and plotted at the Pmp reflection point. Red solid line: true $V_{p}^{u m}=8.30 \mathrm{~km} / \mathrm{s}$. Red dashed lines: $\pm 1.5 \%$ perturbation from the true $V_{p}^{u m}$. (g) Back-projection image of the pseudo-P-component synthetic data corrected to $90^{\circ}$ phase shift (vertical exaggeration $\times 7.5$ ). Gray line: true CMB depth. Black dashed box is area enlarged in (k). (h) Enlargement of yellow box in (a) with traced S rays plotted in red. (i) As (h), but plotting Pmp rays traced with the theoretical $S s$ ray parameters (thick gray curve in (d)). (j) As (i), but plotting Pmp rays traced with apparent $S s$ ray parameters (thin black curve in (d)). (k) Enlargement of black dashed box in (g). Black solid curve: the maximum amplitude at each horizontal location picked as the observed Moho depth ("corrected Moho"). Black dashed curve: observed Moho depths from back-projection images assuming a constant ray parameter $(0.1275$ $\mathrm{s} / \mathrm{km}$ ) and zero travel-time residual (i.e. assuming a 1D earth model) ("uncorrected Moho"). (1) waveforms recorded at the green, cyan and blue stations in (a), colored accordingly. 
In review with Geophysical Journal International

(a)

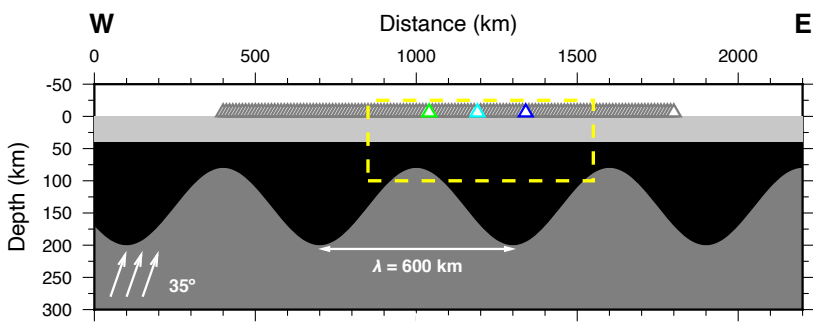

(b)

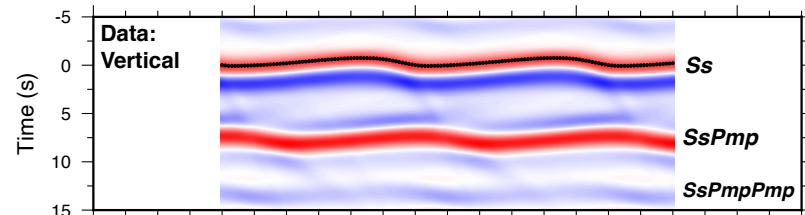

(c)

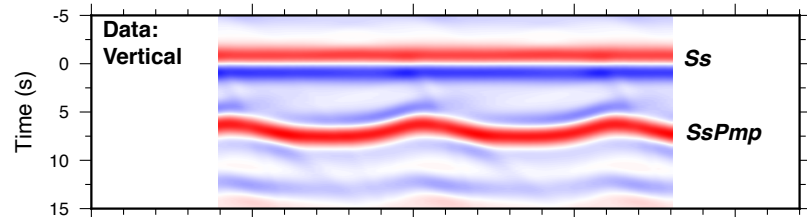

(d)

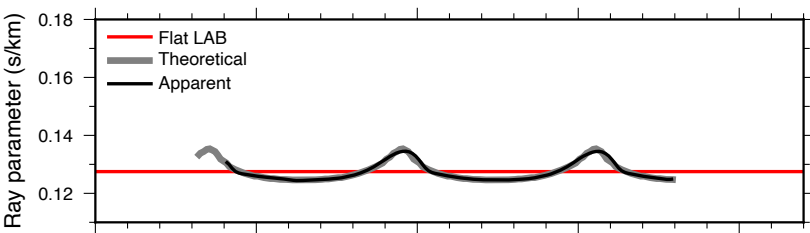

(e)

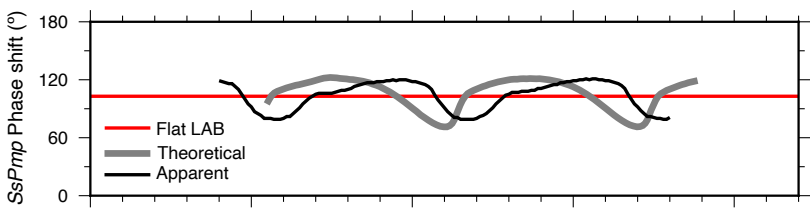

(f)

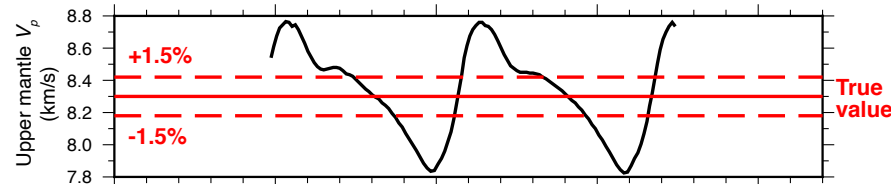

(g)

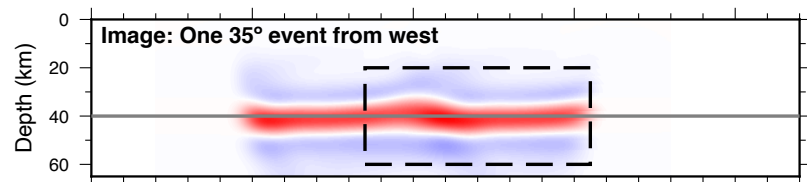

(h)

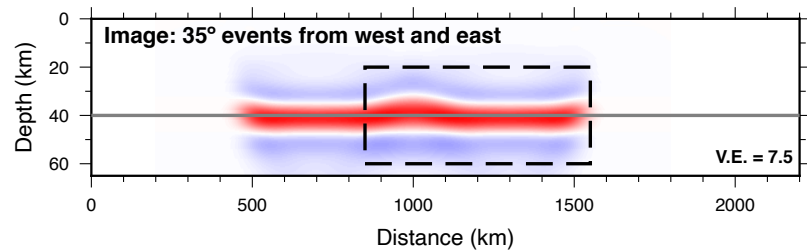

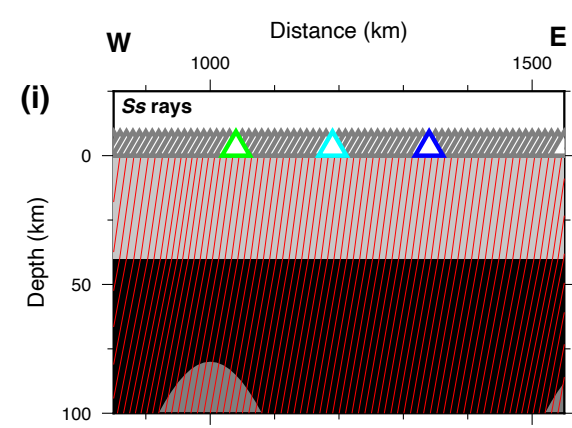
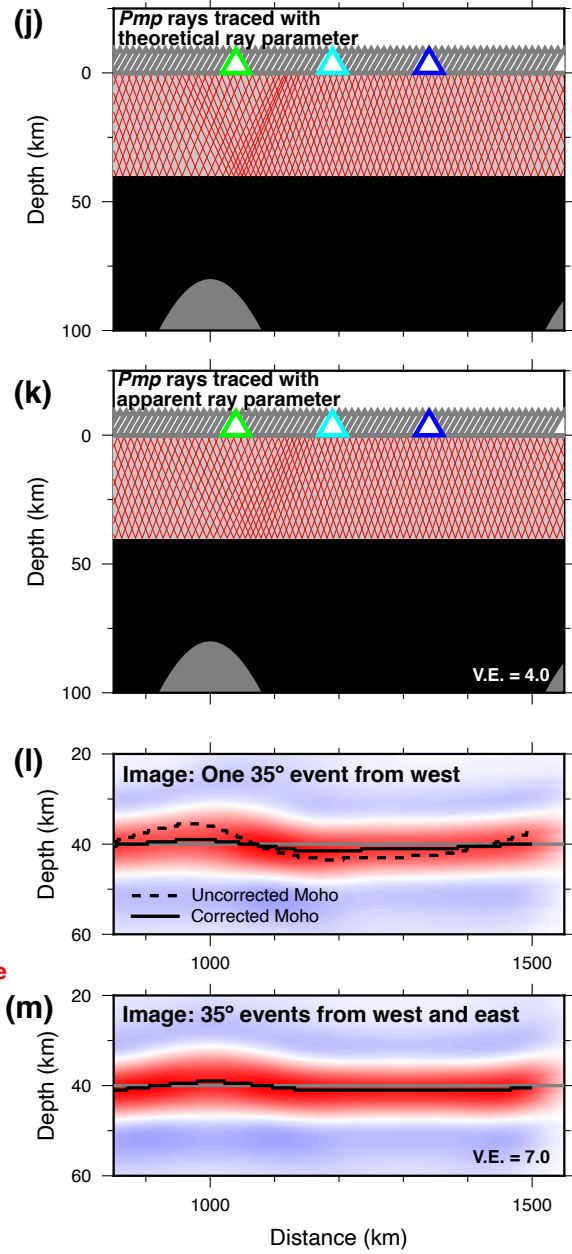

(n)

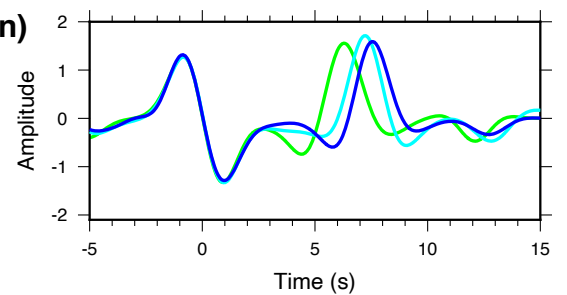


In review with Geophysical Journal International

Figure 3. As Fig. 2, now computed with a $600 \mathrm{~km}$-wavelength LAB $\left(\theta_{a v}=\sim 22^{\circ}\right)$. (h) and (m) are stacked back-projection images of two events with the same incident angle $\left(35^{\circ}\right)$

(a)

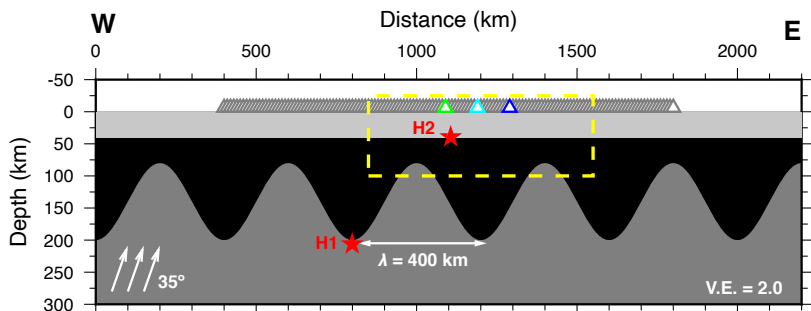

(b)

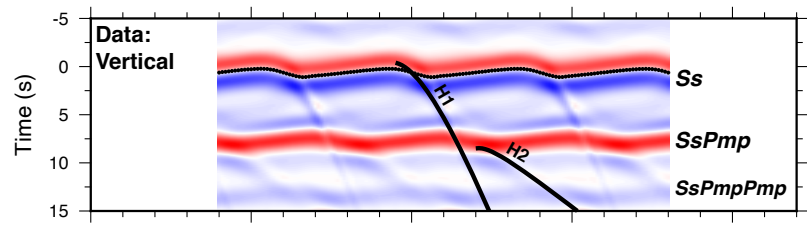

(c)

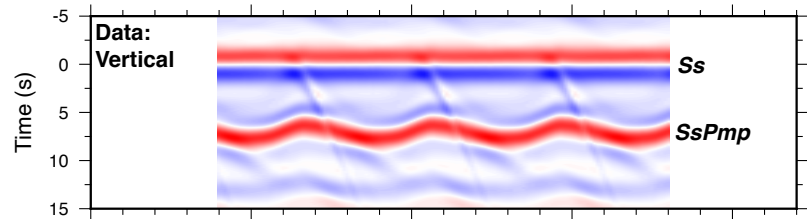

(d)

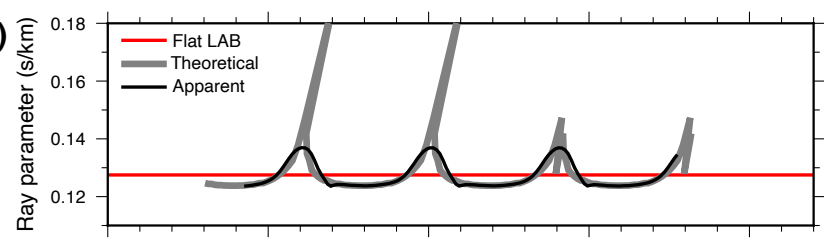

(e)

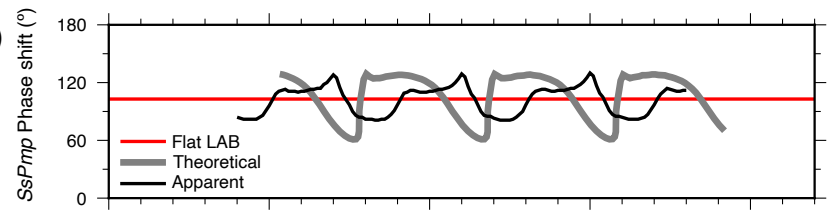

(f)

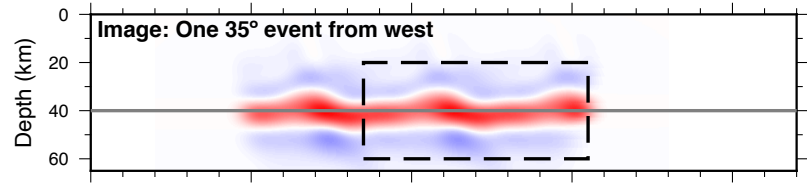

(g)

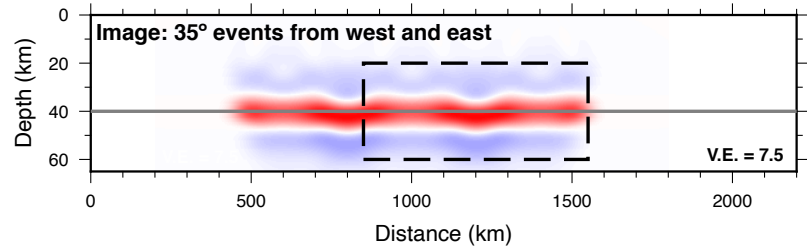

(h)

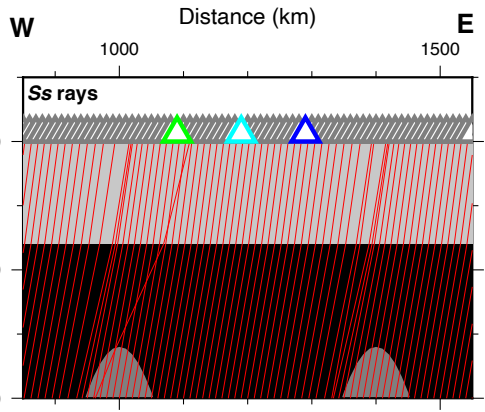

(i)

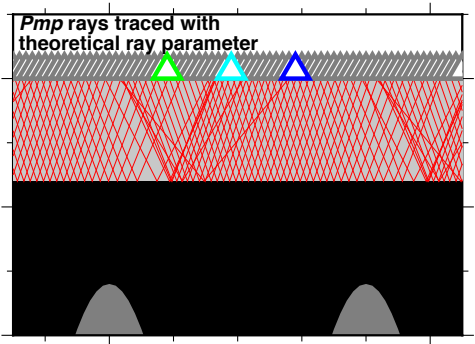

)
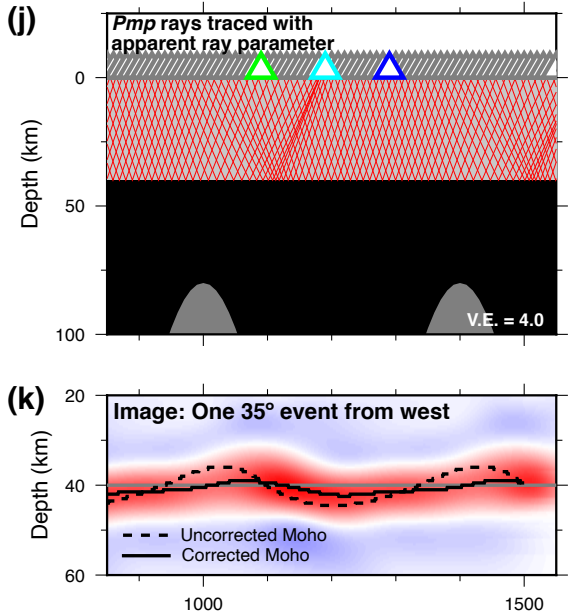

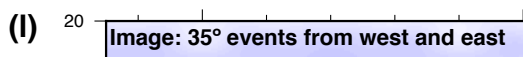

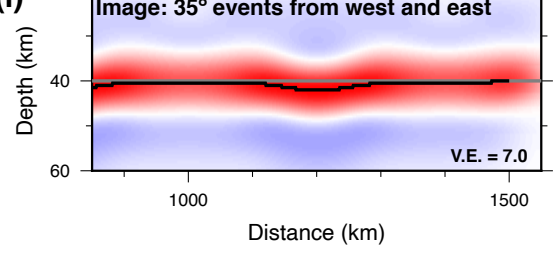

(m)

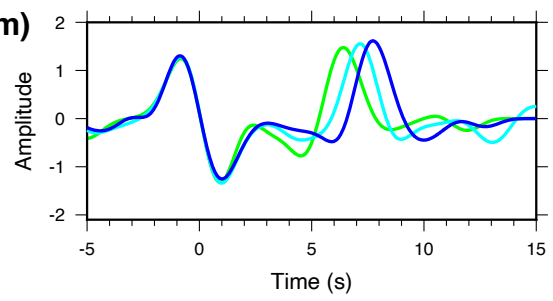

coming from west and east. 
In review with Geophysical Journal International

Figure 4. As Fig. 2, now computed with a $400 \mathrm{~km}$-wavelength LAB $\left(\theta_{a v}=\sim 31^{\circ}\right)$. H1 and $\mathrm{H} 2$ : diffraction hyperbolae computed with source depths and characteristic velocities 200 $\mathrm{km}$ and $4.61 \mathrm{~km} / \mathrm{s}(\mathrm{H} 1)$, and $40 \mathrm{~km}$ and $6.5 \mathrm{~km} / \mathrm{s}(\mathrm{H} 2)$ (red stars). (g) and (l) are stacked back-projection images of two events with the same incident angle $\left(35^{\circ}\right)$ coming from west and east. 
In review with Geophysical Journal International

(a)

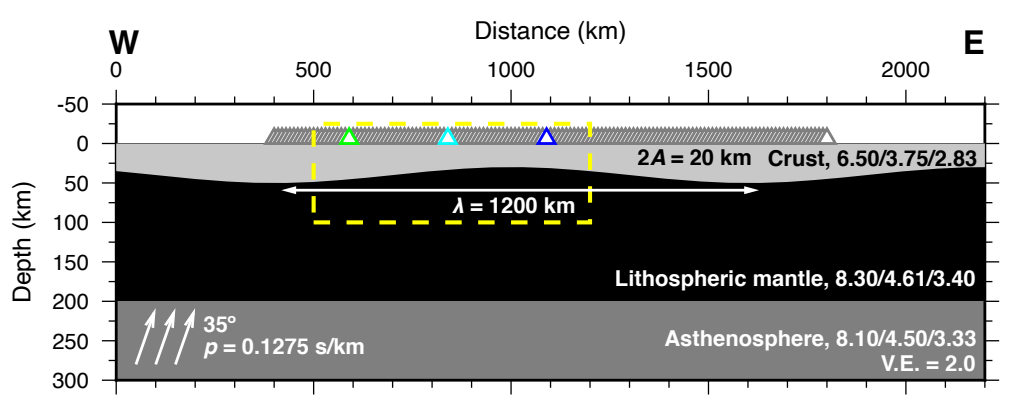

(b)

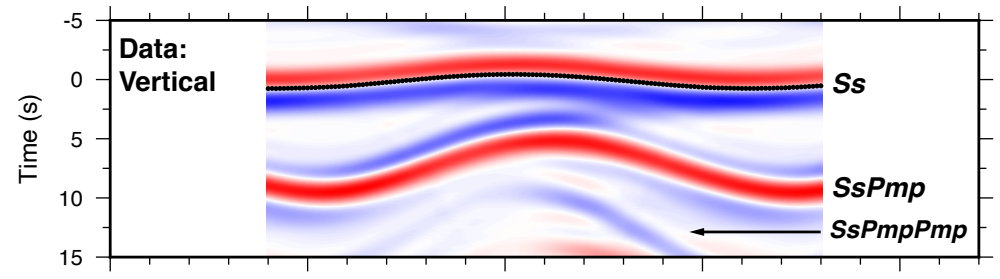

(c)

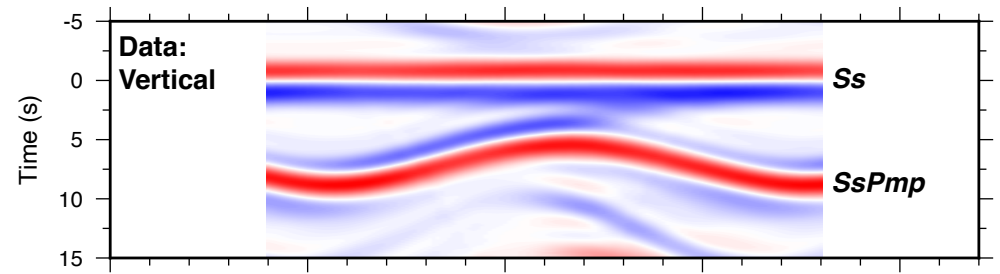

(d)

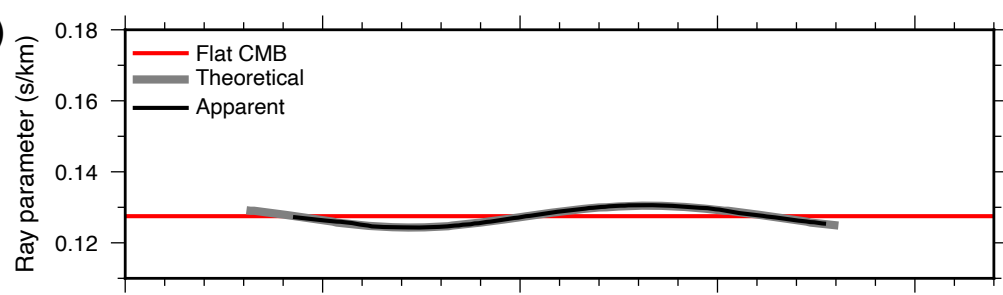

(e)

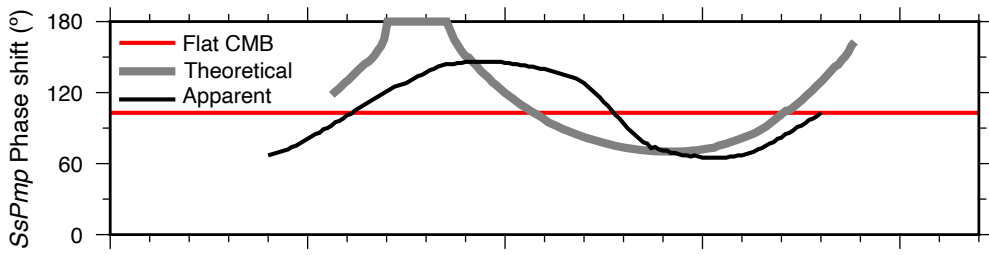

(f)

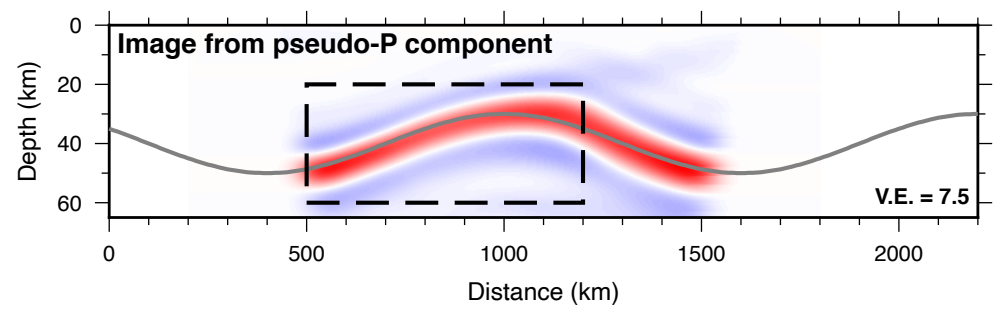

W

Distance $(\mathrm{km})$

E

(g)

$500 \quad 1000$



(h)



(i)

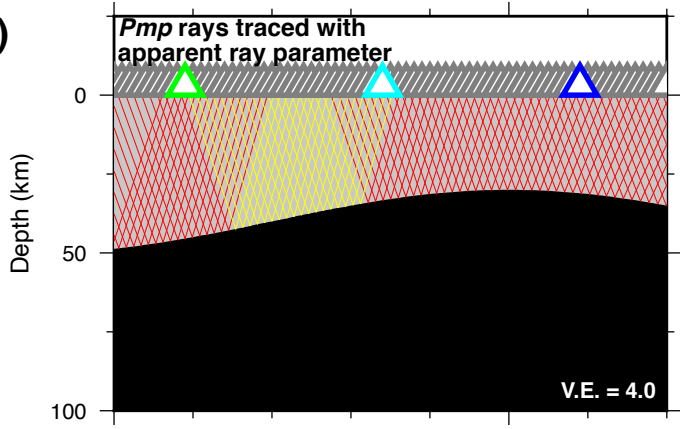

(j)

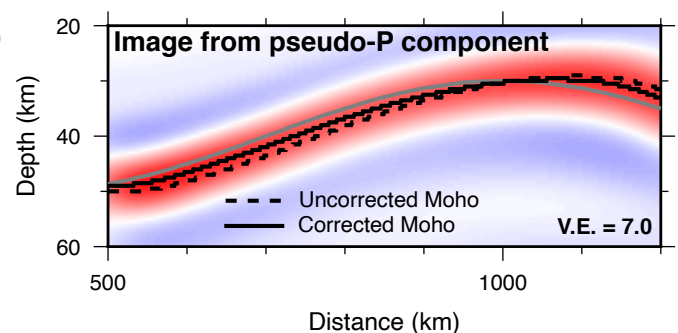

(k)

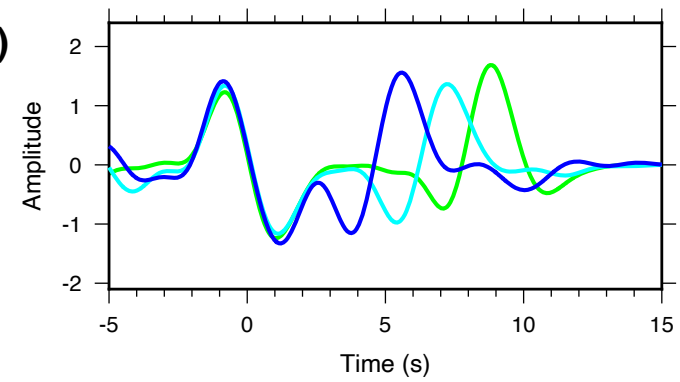


In review with Geophysical Journal International

Figure 5. As Fig. 2, now computed with a $1200 \mathrm{~km}$-wavelength $\mathrm{CMB}\left(\theta_{a v}=\sim 2^{\circ}\right)$ and a flat LAB. Yellow rays (parts $h$ and i) undergo pre-critical reflections at the CMB. 
In review with Geophysical Journal International

(a)

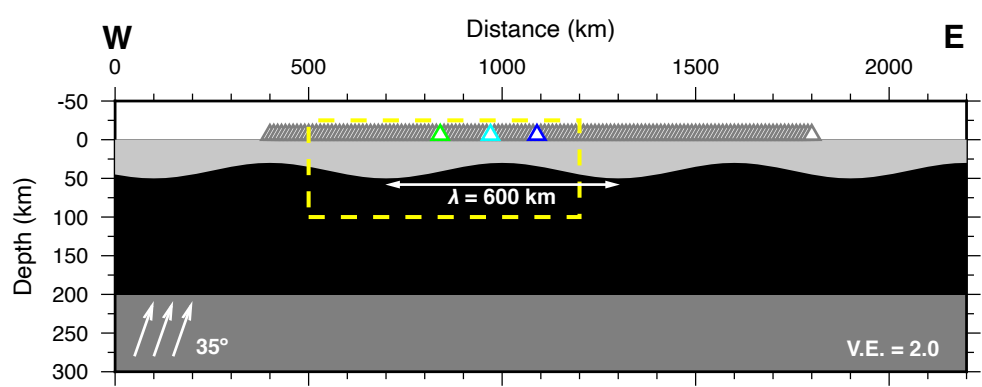

(b)

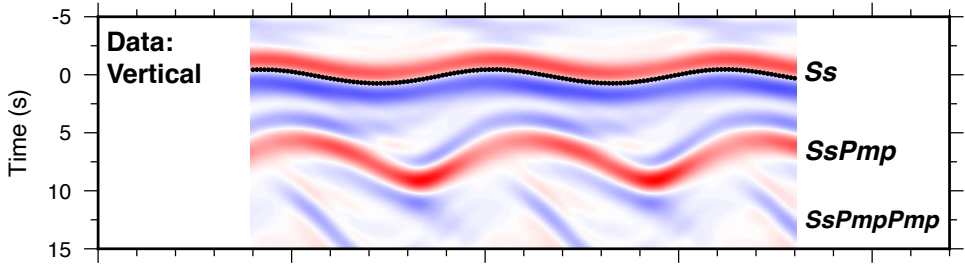

(c)

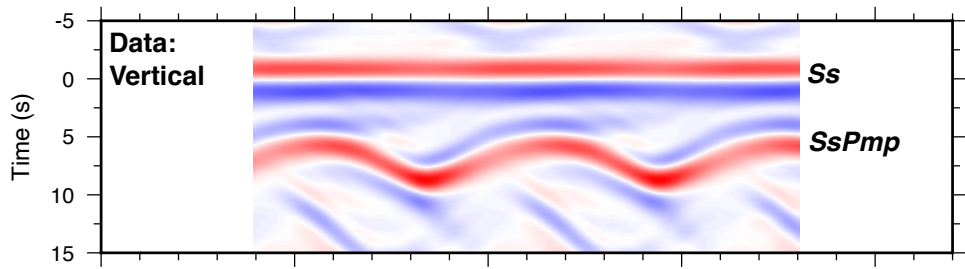

(d)



(e)

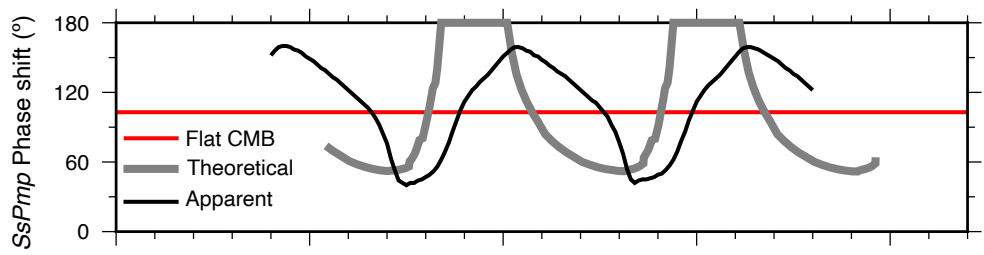

(f)

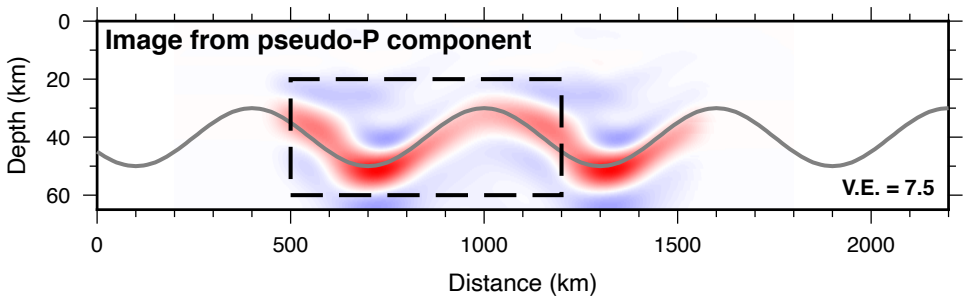

(g)

W

Distance $(\mathrm{km})$

E

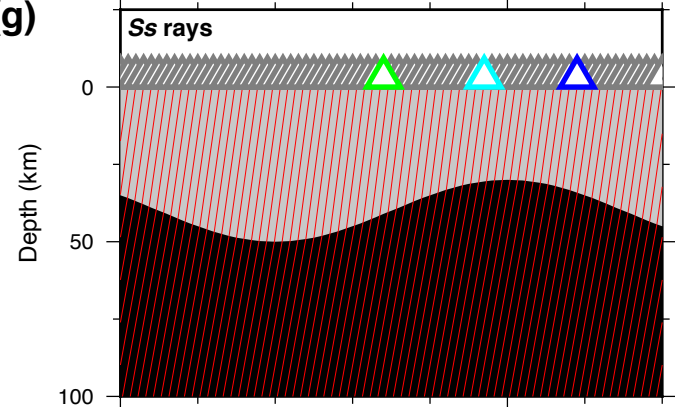

(h)

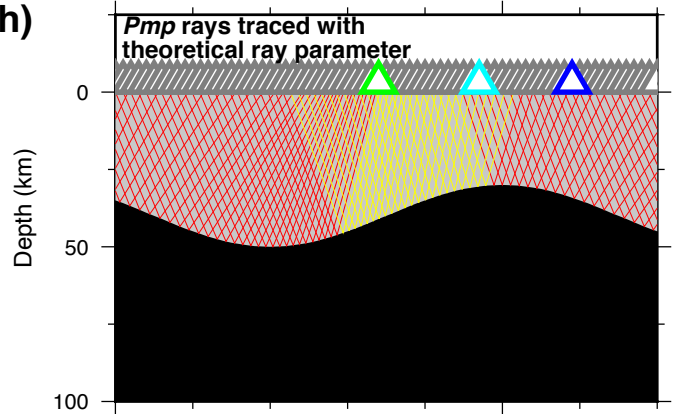

(i)

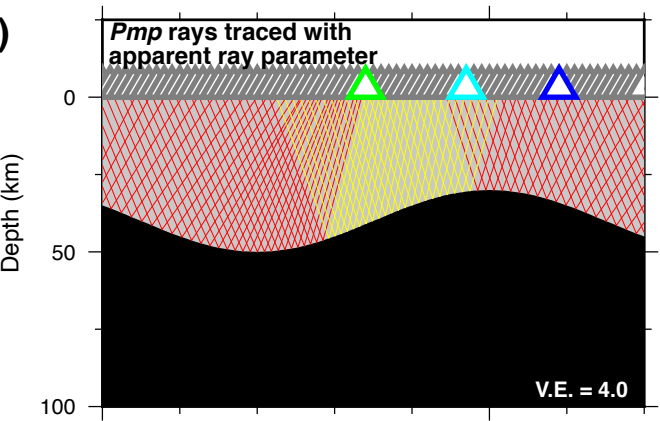

(j)

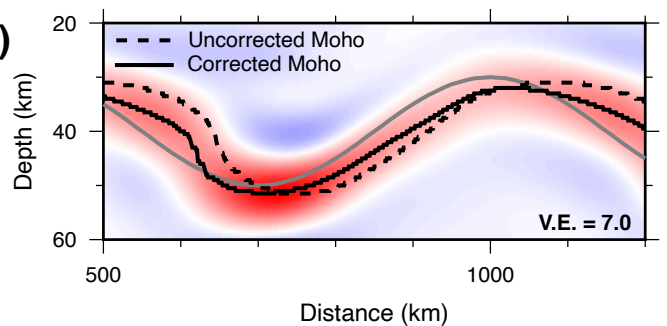

(k)

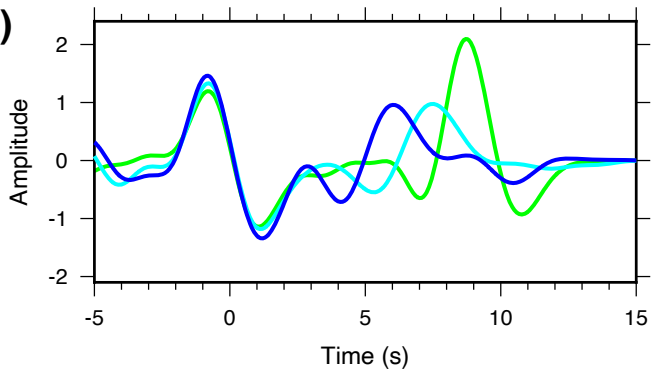

Figure 6. As Fig. 5, now computed with a $600 \mathrm{~km}$-wavelength CMB $\left(\theta_{a v}=\sim 4^{\mathrm{o}}\right)$. 
In review with Geophysical Journal International
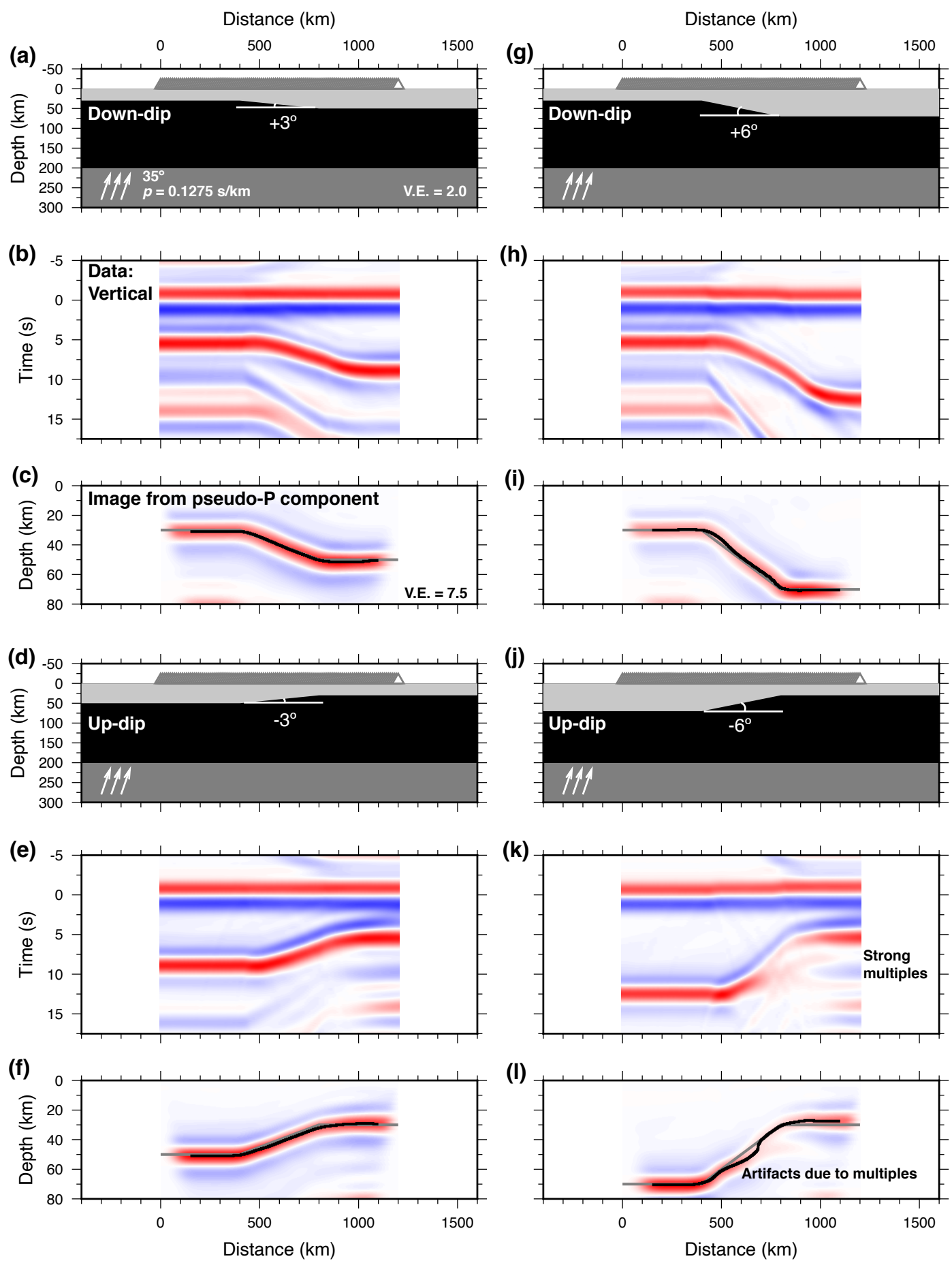

Figure 7. Back-projection images of CMB ramps. (a), (d), (g), and (j) show the models with $\pm 3^{\circ}$ - and $\pm 6^{\circ}$-dip ramps respectively. Model parameters for the crust, mantle lithosphere and asthenosphere are the same as all the other cases. Incident angle of the incoming S wave is also $35^{\circ}$. (b), (e), (h), and (k) are the vertical component waveforms computed with the models in (a), (d), (g), and (j) respectively. (c), (f), (i), and (l) show the corrected back-projection images derived from (b), (e), (h), and (k) respectively. Note 
that the CMB dips are well-recovered in all cases except for a segment in (h) where strong multiples following SsPmp cause local artifacts.

(a)

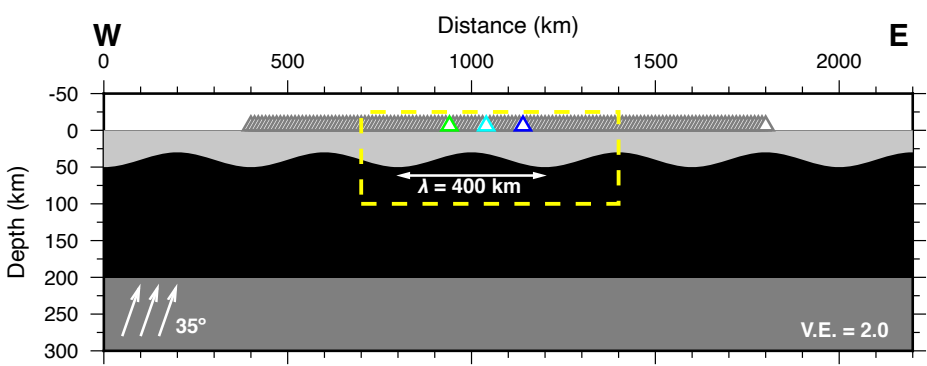

(b)

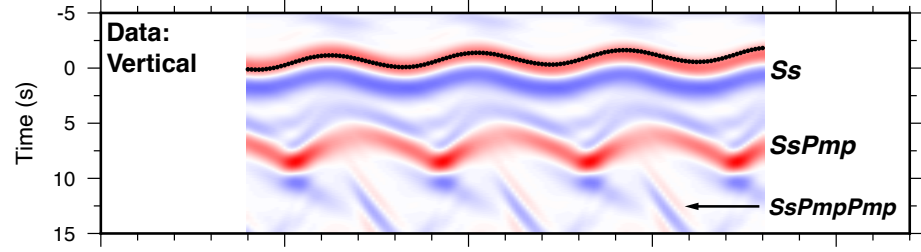

(c)

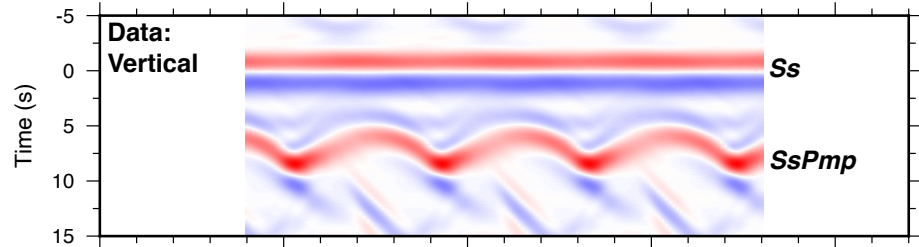

(d)



(e)

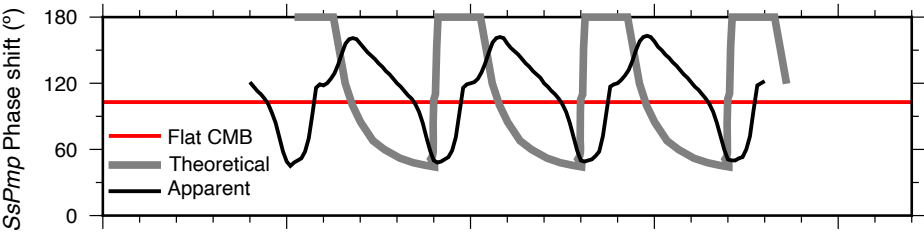

(f)

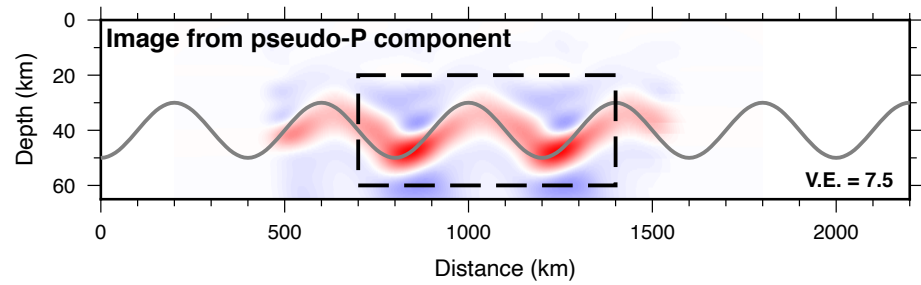

(g)



(h)

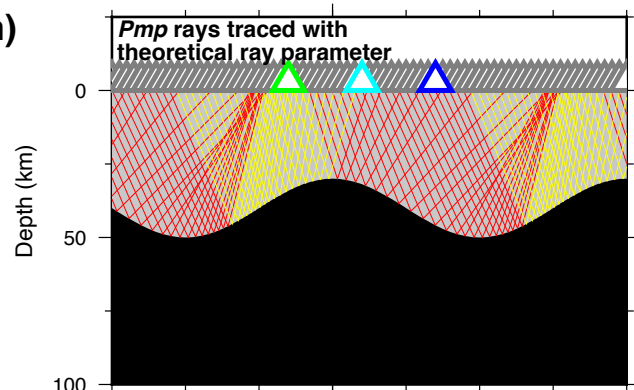

(i)

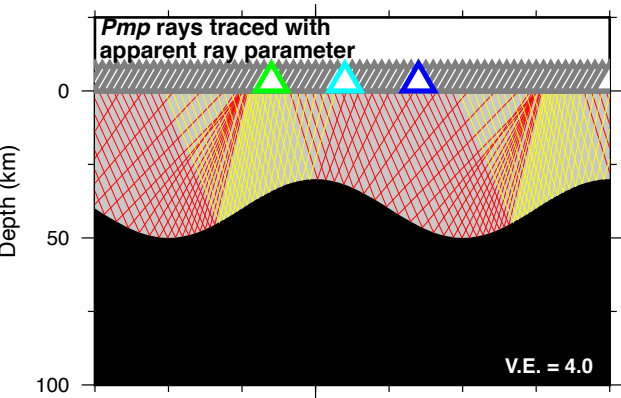

(j)

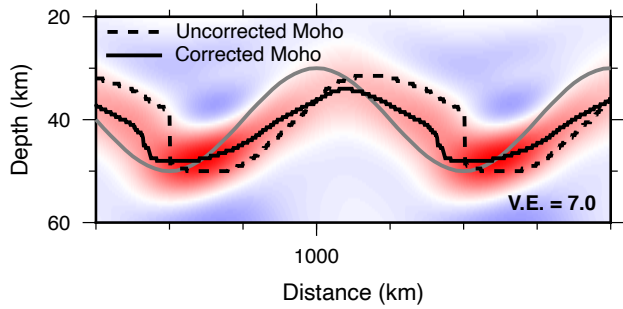

(k)

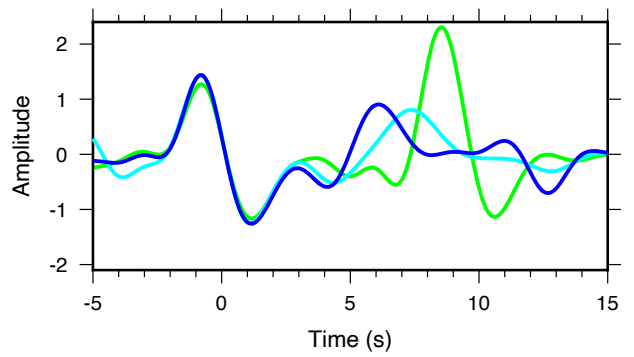


In review with Geophysical Journal International

Figure 8. As Fig. 5, now computed with a $400 \mathrm{~km}$-wavelength $\operatorname{CMB}\left(\theta_{a v}=\sim 6^{\circ}\right)$.

(a)

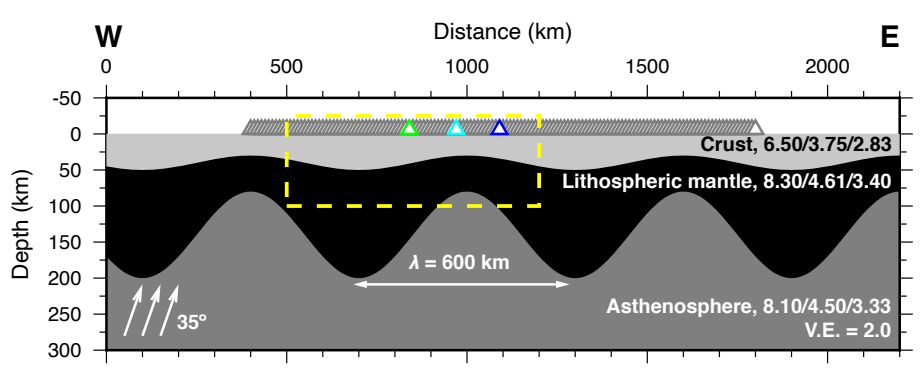

(f)

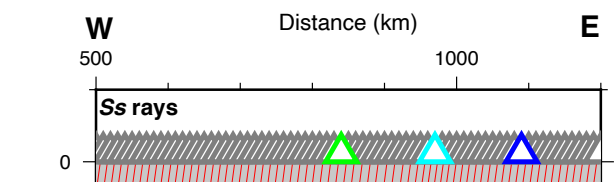

(b)

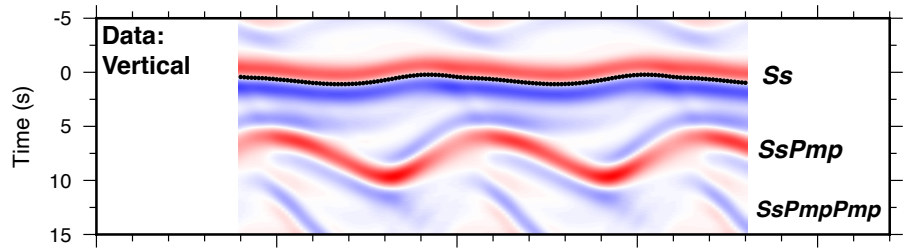

(c)

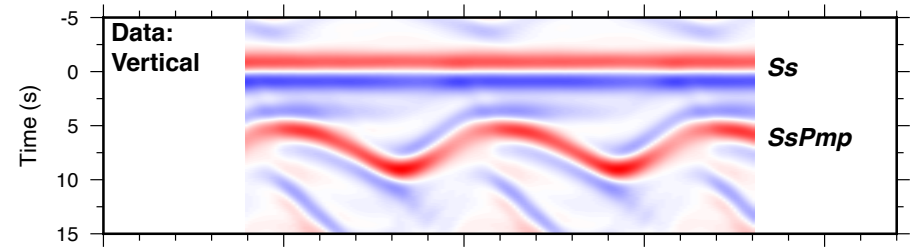

(d)

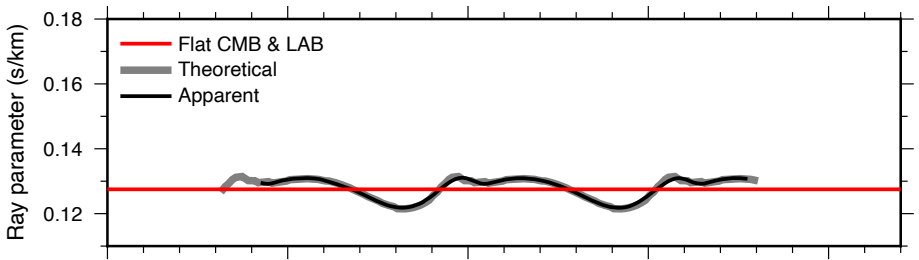

(h)
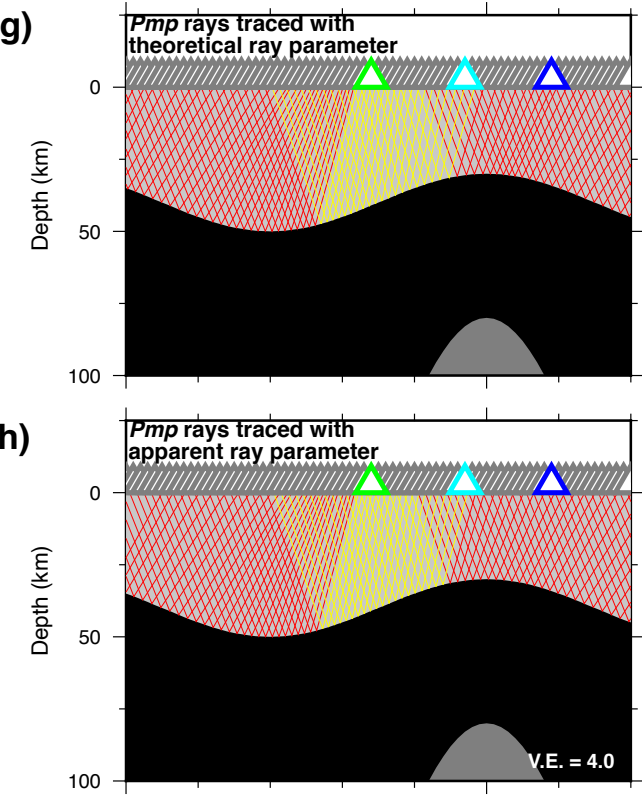

(e)



(i)

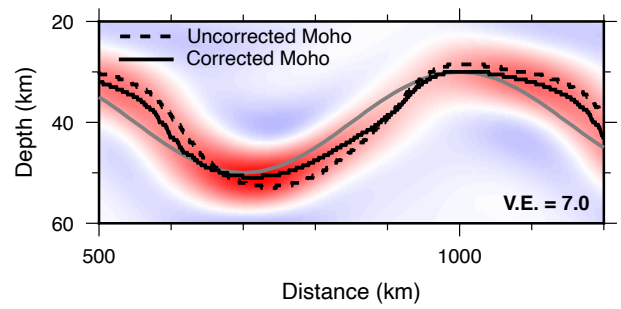

(j)

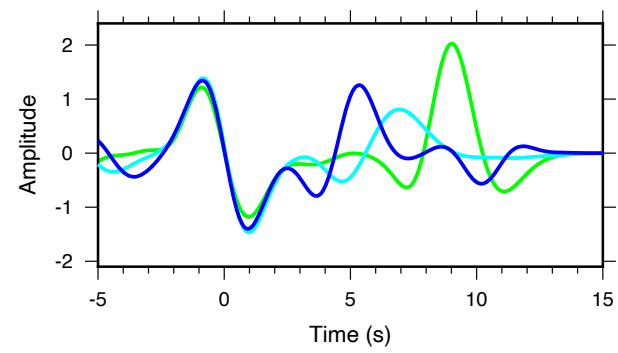


In review with Geophysical Journal International

Figure 9. As Fig. 8, now computed with $600 \mathrm{~km}$-wavelength CMB $\left(\theta_{a v}=\sim 4^{\circ}\right)$ and LAB $\left(\theta_{a v}=\sim 22^{\circ}\right)$.

\section{$3 \mathbf{k m}$-deep basin}

(a)

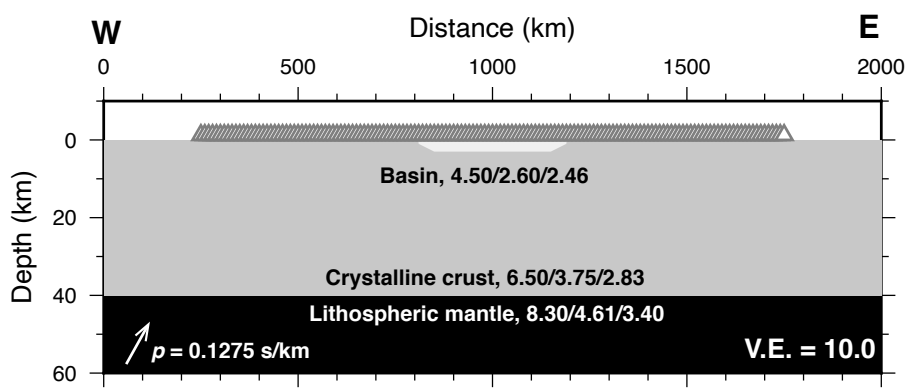

(b)

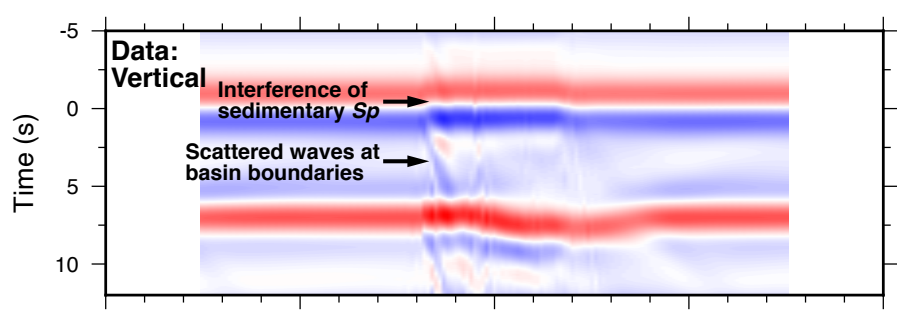

(c)

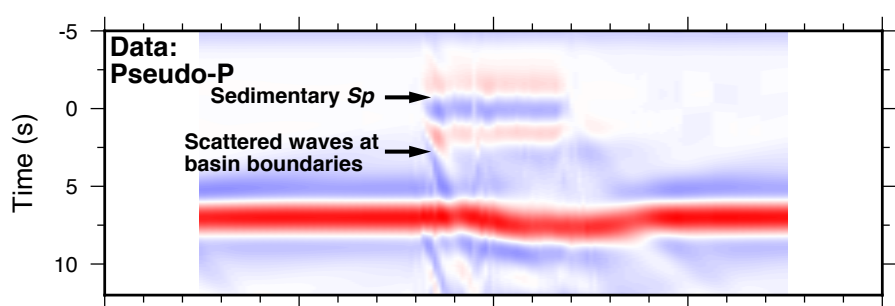

(d)

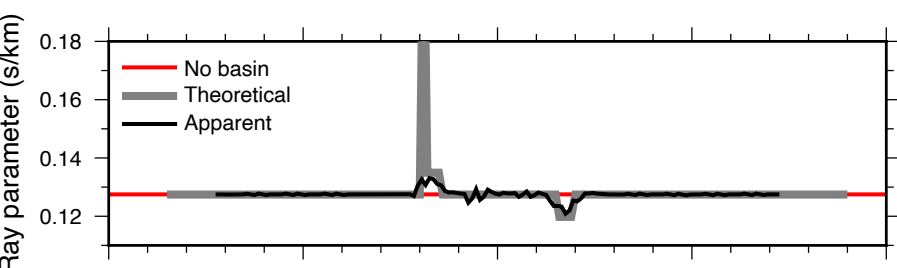

(e)

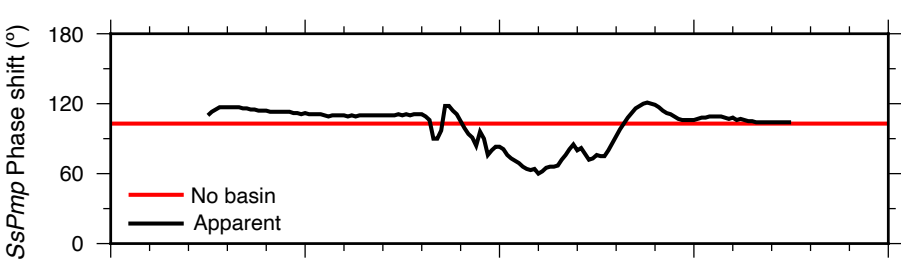

(f)

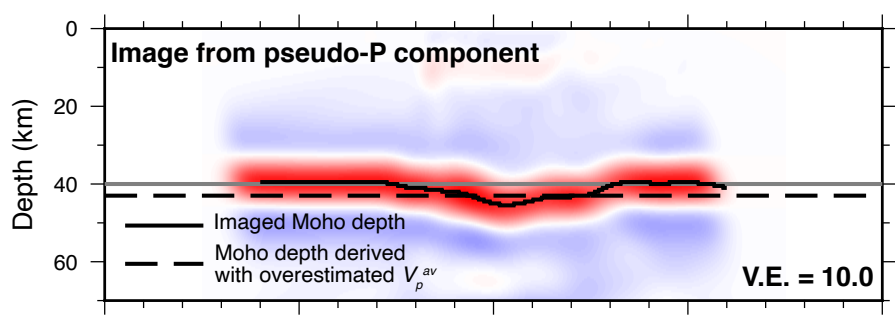

\section{$6 \mathrm{~km}$-deep basin}

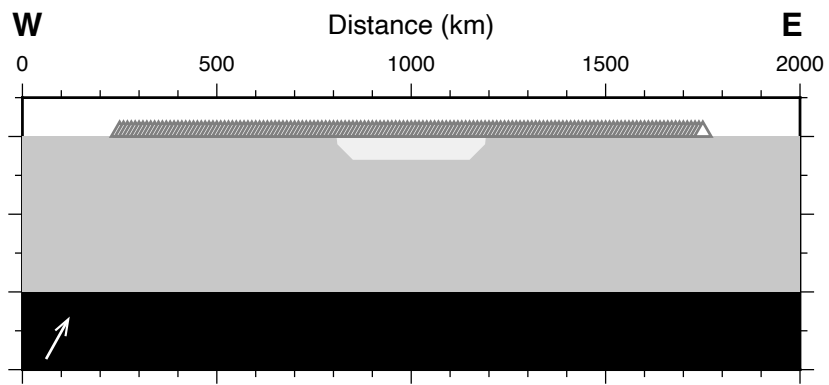

(h)

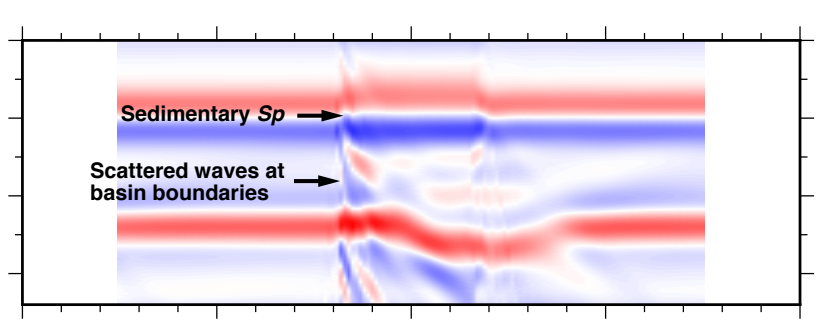

(i)

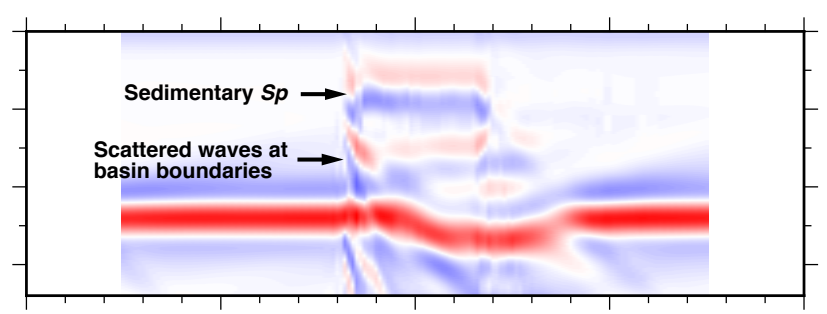

(j)

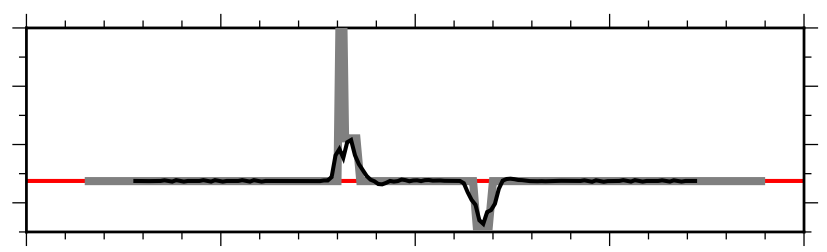

(k)

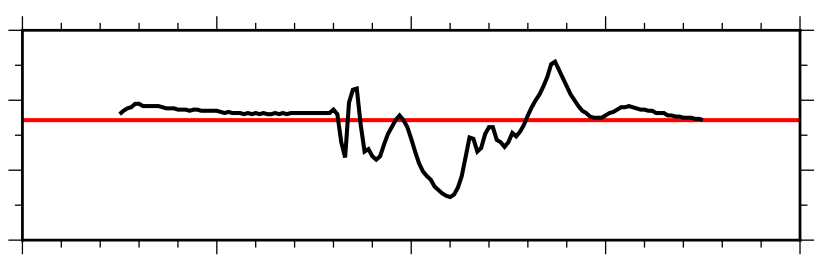

(I)

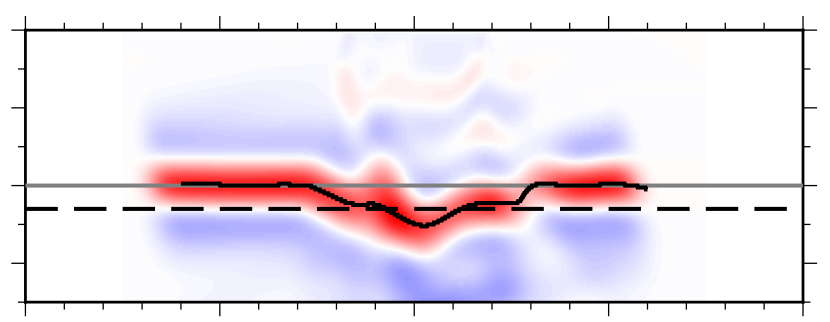


In review with Geophysical Journal International

Figure 10. Back-projection imaging in the presence of sedimentary basins. (a) and (g) show the models with a $3 \mathrm{~km}$ - and $6 \mathrm{~km}$-deep moderate-velocity sedimentary basins $\left(V_{p}=\right.$ $4.5 \mathrm{~km} / \mathrm{s}, V_{s}=2.6 \mathrm{~km} / \mathrm{s}$, density $\left.=2.46 \mathrm{~g} / \mathrm{cm}^{3}\right)$. Other model parameters are as in the previous models, except the CMB is flat at $40 \mathrm{~km}$ depth, and the LAB flat at $120 \mathrm{~km}$ depth. The edges of the basins dip at $\sim 3^{\circ}$ and $\sim 6^{\circ}$ in (a) and (g) respectively. (b) and (h) show the vertical-component seismograms computed with (a) and (g) respectively. (c) and (i) show the pseudo-P-component seismograms derived from (b) and (h). (d) and (j) show the apparent and theoretical $p_{S s .}$ (e) and (k) show the apparent $\Phi_{V D S S .}(\mathrm{f})$ and (l) show the back-projection images derived from (c) and (i). The the deeper Moho imaged beneath the basins in (f) and (l) is mostly due to the low average crustal velocity caused by the basins. 

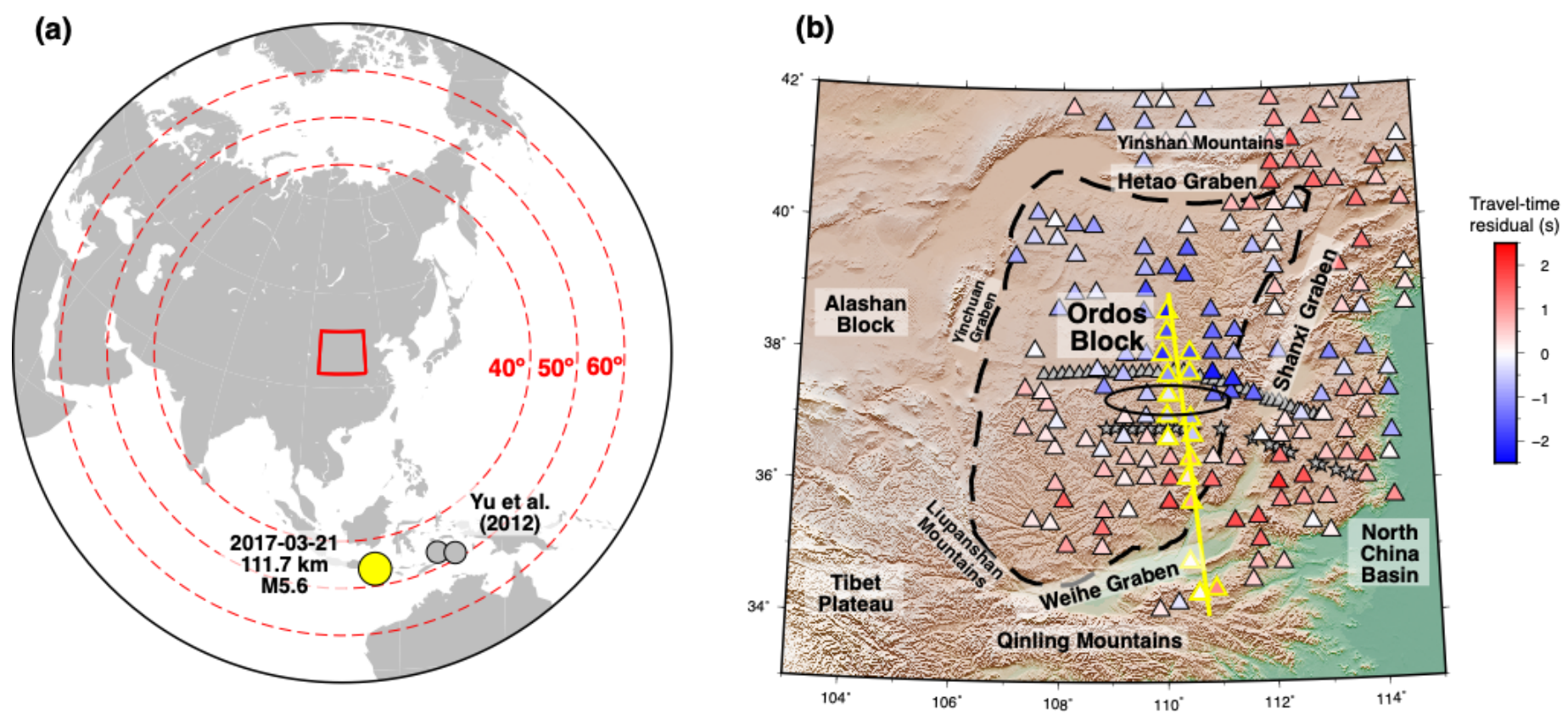

Figure 11. ChinArray over the Ordos Plateau. (a) Study area (red box) and the studied event (yellow circle). Gray circles: events used by Yu et al. (2012). (b) ChinArray stations (2D array recording 2016-2017) and the stations used in Yu et al. (2012) (dense linear array recording 2007-2008). The ChinArray stations are colored by their $S s$ traveltime residuals with respect to the AK135 model. Yellow solid line marks the profile shown in Fig. 13. Stations with yellow edges are the ones within $30 \mathrm{~km}$ of, and projected onto the yellow line. Small gray triangles and stars: stations and corresponding virtual sources in Yu et al. (2012). Black oval: approximate region of overthickened crust shown in Yu et al. (2012). Black dashed line: boundary of the Ordos Block. 
In review with Geophysical Journal International

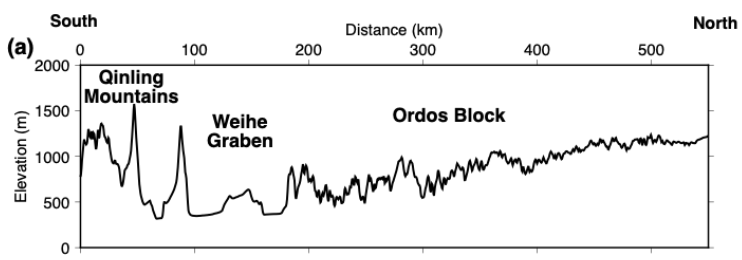

(b)
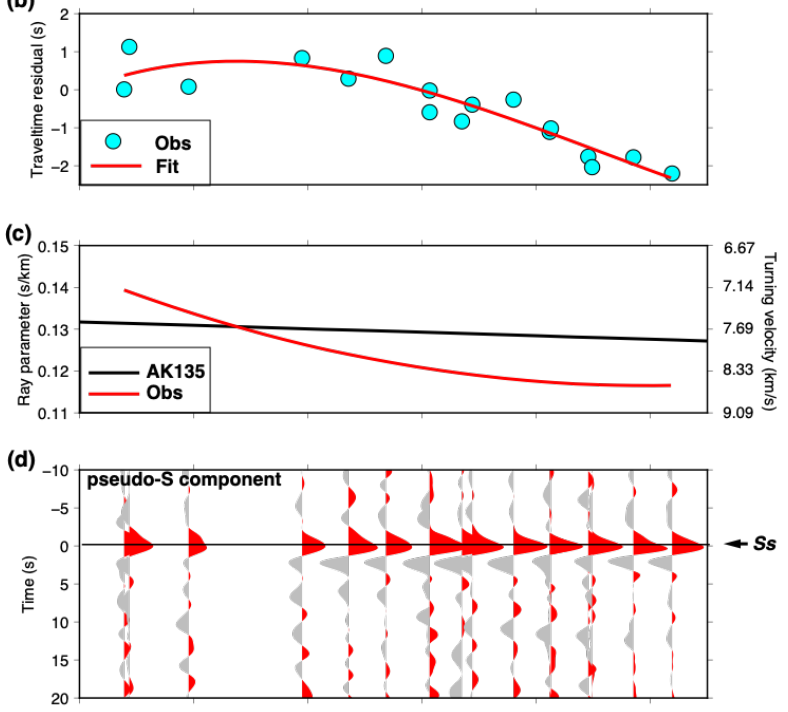

(e)
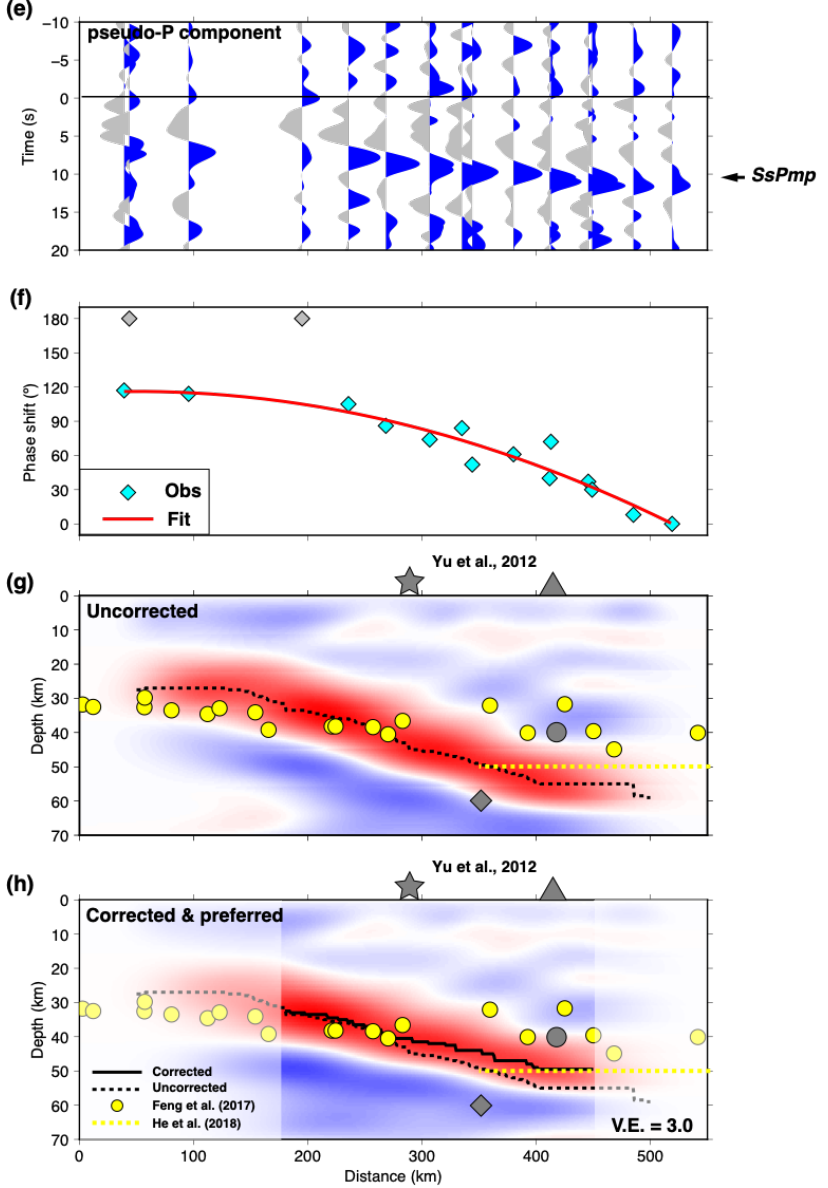
Figure 12. Back-projection results using the ChinArray dataset. All profiles are along the yellow line in Fig. 11b. (a) Topography. (b) Ss travel-time residuals. Cyan circles: Ss residuals measured on individual stations. Red curve: travel-time residual computed by fitting a third-degree polynomial to the measurements. (c) Ray-parameter variation. Black: ray parameter computed with the AK135 model. Red: observed ray parameter computed by differentiating the fitted travel residual with respect to distance and adding it to the ray-parameter computed with AK135. (d) and (e) pseudo-S- and pseudo-Pcomponent seismograms recorded at the stations along the profile, aligned to observed $S s$ arrival times. (f) $\Phi_{V D S S}$. Diamonds: measured $\Phi_{V D S S}$ from each pseudo-P-component trace along the profile. Cyan diamonds were used to fit the curve; two gray diamonds were excluded. Red curve: $\Phi_{V D S S}$ as a function of distance computed by fitting a second-degree polynomial to the observations. (g) and (h) Back-projection images along the profile with $\times 3$ vertical exaggeration. Both $(\mathrm{g})$ and $(\mathrm{h})$ are derived with phase-shift of each trace corrected to $0^{\circ}$ using the fitted $\Phi_{V D S S}$ as a function of distance. $V_{p}{ }^{a v}=6.2 \mathrm{~km} / \mathrm{s}$ is assumed for both $(\mathrm{g})$ and $(\mathrm{h}) .(\mathrm{g})$ is computed with zero travel-time residual and the ray parameter predicted by AK135 (uncorrected). (h) is computed with the observed travel-time residuals and ray parameters (corrected \& preferred). Solid and dotted black curves: Moho depth picks (maximum amplitude at every location along the profile) for the corrected and uncorrected Moho images (same convention as in the synthetic examples). White translucent rectangles mask areas with less reliable corrected Moho estimations. Gray triangle and star: approximate locations of station and VDSS virtual source respectively from Yu et al. (2012). Gray circle: RF Moho depth from Yu et al. (2012) plotted right below the station. Gray diamond: VDSS Moho depth from Yu et al. (2012) plotted at the approximate reflection point. Yellow circles: RF Moho depth measurements from Feng et al. (2017) on stations within $30 \mathrm{~km}$ of the profile. Yellow dotted lines: approximate extent and depth of the bottom of the crustal growth zone from $\mathrm{He}$ et al. (2018). Beyond $250 \mathrm{~km}$, the corrected Moho (part h) is significantly shallower than the uncorrected Moho (part g) and is more consistent with the RF measurements. 


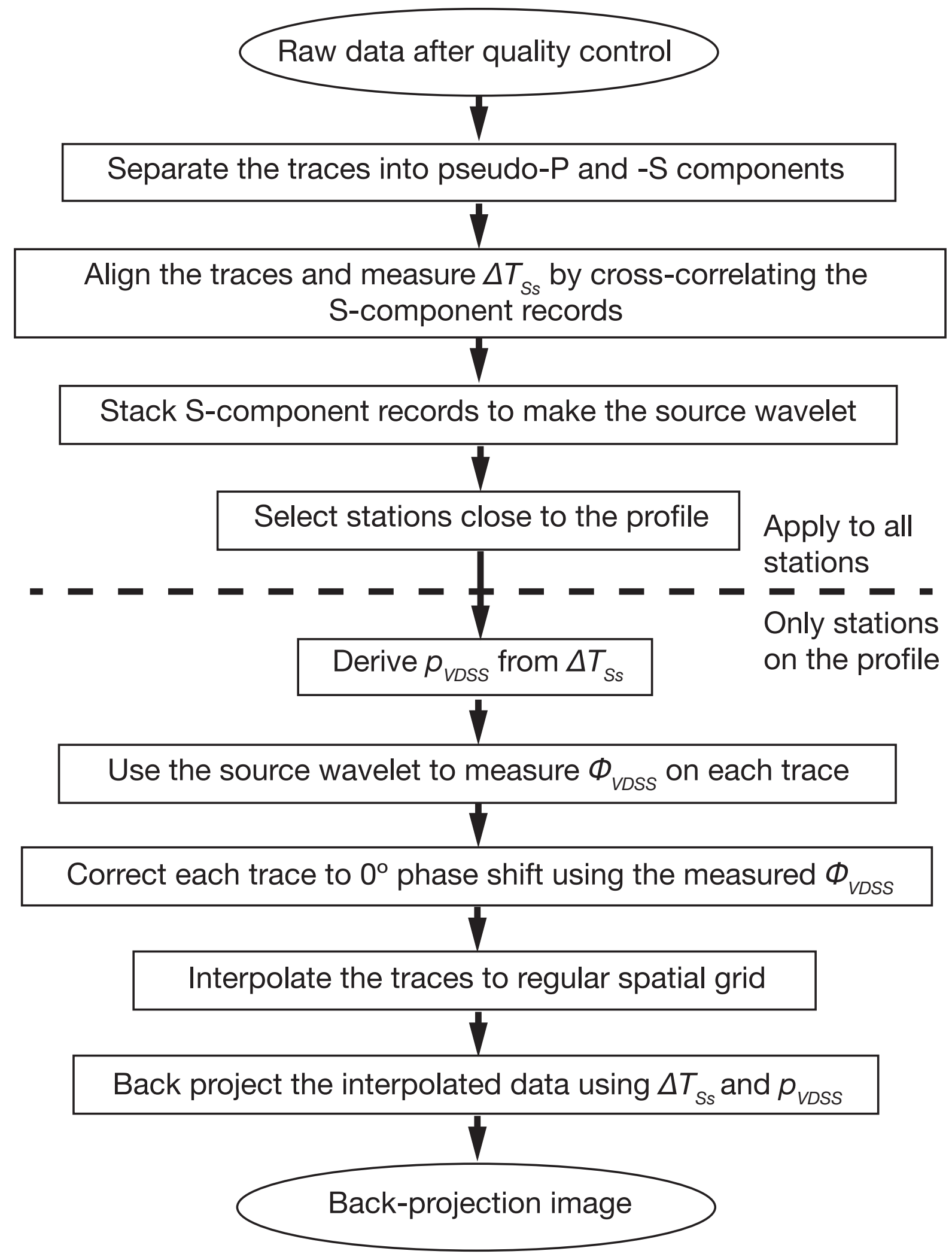

Figure 13. Processing workflow for the Ordos dataset. 
In review with Geophysical Journal International

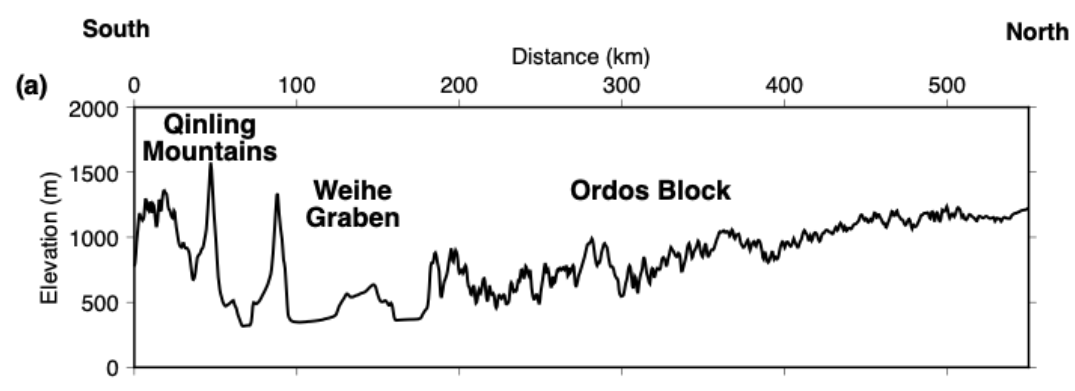

(b)

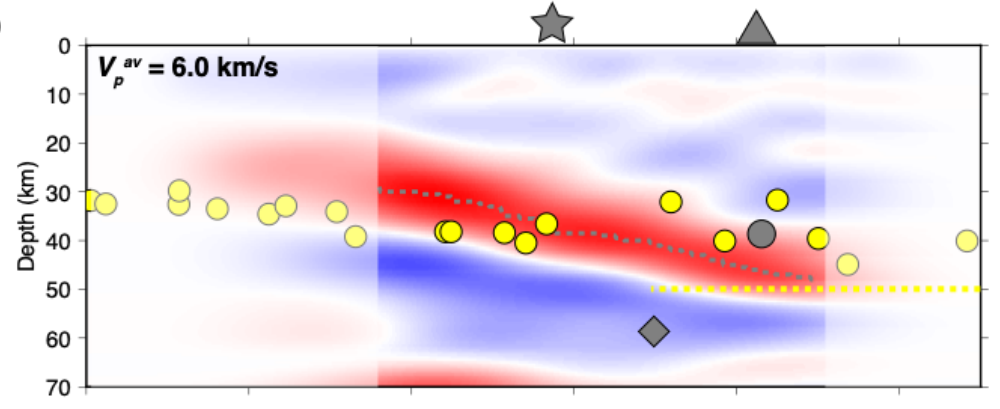

(c)

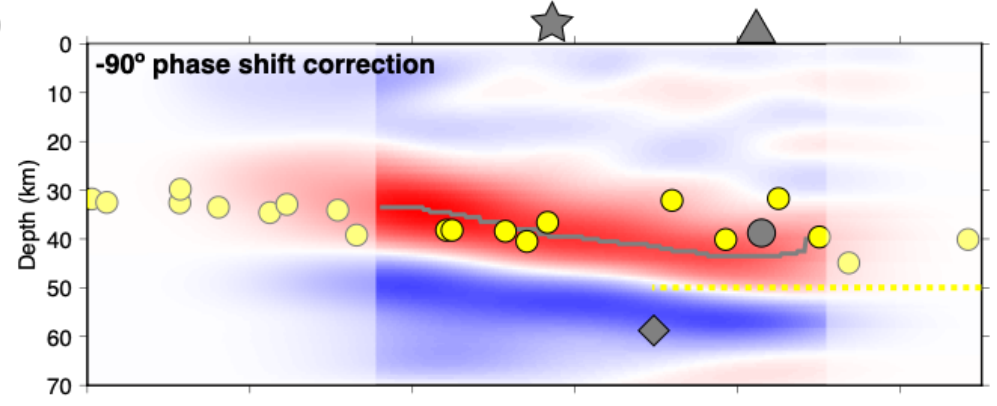

(d)

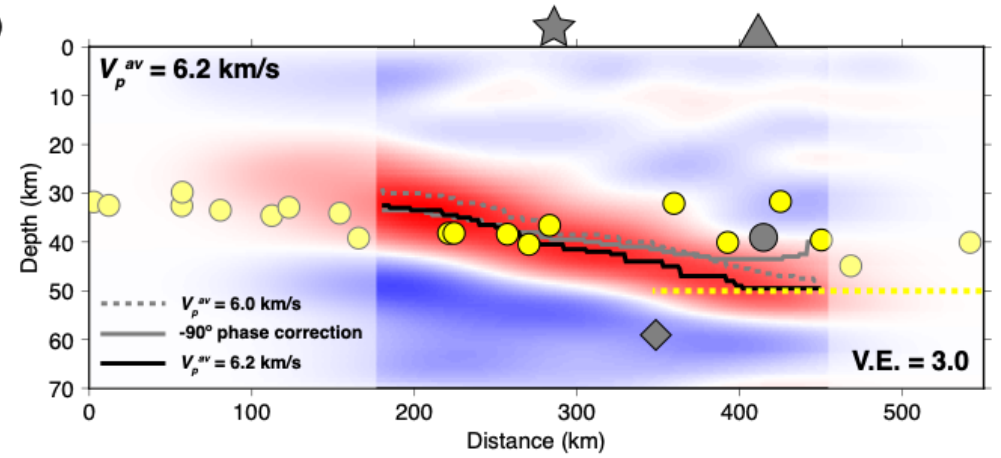

Figure 14. Effects of processing parameters on Moho depth estimations along the profile in Fig. 12. Moho depths from previous studies are denoted as in Fig. 12. (a) The same as Fig. 12a. (b) As Fig. 12h, but computed with $V_{p}{ }^{a v}=6.0 \mathrm{~km} / \mathrm{s}$. Gray dotted curve: Moho depth picks. (c) As Fig. 12h, but computed with a $-90^{\circ}$-phase-shift correction applied to each trace. Gray solid curve: Moho depth picks. (d) The same as Fig. 12h. Black solid curve: Moho depth picks of this image. Gray dotted and solid curves: Moho depth picks in (b) and (c), respectively. 